NBER WORKING PAPER SERIES

\title{
PARENTS' BELIEFS ABOUT THEIR CHILDREN'S ACADEMIC ABILITY: IMPLICATIONS FOR EDUCATIONAL INVESTMENTS
}

\author{
Rebecca Dizon-Ross \\ Working Paper 24610 \\ http://www.nber.org/papers/w24610
NATIONAL BUREAU OF ECONOMIC RESEARCH
1050 Massachusetts Avenue
Cambridge, MA 02138
May 2018

I am very grateful to Pascaline Dupas, Caroline Hoxby, and Seema Jayachandran for their guidance, and to Ran Abramitzky, Abhijit Banerjee, Jim Berry, Marianne Bertrand, Nick Bloom, Doug Bernheim, Eric Budish, Manasi Deshpande, Celine Dizon, Elise Dizon-Ross, Natalie Douvos, Esther Duflo, Alex Eble, Liran Einav, Nick Hagerty, Rema Hanna, Johannes Haushofer, Yael Hochberg, Anil Jain, Asim Khwaja, Anjini Kochar, Dan Lee, Shirlee Lichtman, Matthew Lowe, Rachael Meager, Ben Olken, Arianna Ornaghi, Jonah Rockoff, Sheldon Ross, Ashish Shenoy, Fabiana Silva, Melanie Wasserman, Tom Wollmann, Jenny Ying, Owen Zidar and workshop participants at Stanford, MIT, and Harvard, and seminar participants at Princeton, Yale, Columbia, University of Chicago, Chicago Booth, Northwestern, Harvard Business School, Stanford GSB, UCLA, UCSD, Stanford, Columbia Teacher's College, Duke, NBER Development Fall 2014, NBER Education Spring 2014, PacDEV 2014, and NEUDC 2013 for helpful comments and discussions. I thank Bridget Hoffmann, Rachel Levenson, and Michael Roscitt for help with the fieldwork, and Christine Cai and Yashna Nandan for excellent research assistance. I appreciate the generous support of the Endowment in Memory of B.F. Haley and E.S. Shaw, Innovations for Poverty Action, the National Science Foundation (DDRIG 1156155), the Russell Sage Foundation, the Shultz Graduate Student Fellowship, SIEPR, the Stanford Economics Department, and the DDRO and GRO Funds. This study is registered in the AEA RCT Registry and the unique identifying number is: AEARCTR-0001808. All errors are my own. The views expressed herein are those of the author and do not necessarily reflect the views of the National Bureau of Economic Research.

NBER working papers are circulated for discussion and comment purposes. They have not been peer-reviewed or been subject to the review by the NBER Board of Directors that accompanies official NBER publications.

(C) 2018 by Rebecca Dizon-Ross. All rights reserved. Short sections of text, not to exceed two paragraphs, may be quoted without explicit permission provided that full credit, including () notice, is given to the source. 
Parents' Beliefs About Their Children's Academic Ability: Implications for Educational Investments Rebecca Dizon-Ross

NBER Working Paper No. 24610

May 2018

JEL No. D80,I20,I24,I25

\begin{abstract}
$\underline{\text { ABSTRACT }}$
Information about children's school performance appears to be readily available. Do frictions prevent parents, particularly low-income parents, from acting on this information when making decisions? I conduct a field experiment in Malawi to test this. I find that parents' baseline beliefs about their children's academic performance are inaccurate. Providing parents with clear and digestible academic performance information causes them to update their beliefs and correspondingly adjust their investments: they increase the school enrollment of their higher-performing children, decrease the enrollment of their lower-performing children, and choose educational inputs that are more closely matched to their children's academic level. These effects demonstrate the presence of important frictions preventing the use of available information, with heterogeneity analysis suggesting the frictions are worse among the poor.
\end{abstract}

\author{
Rebecca Dizon-Ross \\ Booth School of Business \\ University of Chicago \\ 5807 South Woodlawn Avenue \\ Chicago, IL 60637 \\ and NBER \\ rdr@chicagobooth.edu
}

A data appendix is available at http://www.nber.org/data-appendix/w24610

A randomized controlled trials registry entry is available at

https://www.socialscienceregistry.org/trials/1808 


\section{Introduction}

It is commonly believed that one reason poor households remain poor is that they lack information that the rich possess (World Bank, 1998, 2008). Indeed, there is extensive evidence that providing information to poor individuals affects their decision-making across many domains including health (e.g., Dupas (2011)), education (e.g., Jensen (2010)), and labor supply (e.g., Chetty and Saez (2009)). However, the vast majority of this evidence concerns information that even richer households may not have or use, such as the economic returns to education or market-level summary statistics. The question remains whether frictions prevent the poor from taking advantage of information that seems available to all, but which perhaps only those in richer households or countries can access and exploit.

I examine these issues in a high-stakes environment: Parents making decisions about their children's education. It is widely presumed that the correct educational decisions (such as whether to go to college or sign up for remedial tutoring) vary across individuals. Anecdotally, in developing countries, the most important child-specific factor that determines parents' educational decisions is their children's school performance. School performance information also appears to be freely available: schools worldwide deliver report cards to parents that contain this information, and parents can also observe their children's academic skills directly. And yet, there may be barriers preventing some parents from making use of this information (Banerjee et al., 2010). For example, parents in developing countries are often illiterate and may not be able to read or understand report cards. Limited education may also make it difficult for parents to judge their children's performance themselves, especially if their children go further in school than they did, as is common in developing countries. ${ }^{1}$

This paper establishes that there are in fact substantial and consequential information frictions among poor parents regarding their children's school performance. ${ }^{2}$ First, I show that many parents in a developing country context have inaccurate beliefs about their children's school performance. Second, I demonstrate that parents base important educational decisions upon their inaccurate beliefs, even though they would like to use the correct information that is, in principle, readily available. Third, I use a randomized experiment to show that a simple informational intervention can significantly alleviate the impacts of limited information: Providing information directly to parents in a clear and digestible way causes parents to update their beliefs and adjust their decisions accordingly. Finally, I provide suggestive evidence on a link between information barriers and poverty, showing that poorer,

\footnotetext{
${ }^{1}$ Free primary schooling in most developing countries only became widely available in the last 10-20 years, and the average adult in sub-Saharan Africa has fewer than 5 years of education (UNESCO, 2013).

${ }^{2}$ Although this paper does not claim to distinguish between the various frictions at play, they may include parental illiteracy, limited parental ability to directly assess academic skills, the complexity of existing report cards, and problems with the report card delivery mechanism.
} 
less-educated parents have less accurate baseline beliefs than richer parents, and that both their beliefs and certain investments respond more to information.

I demonstrate these findings by conducting a randomized field experiment in Malawi. The experiment delivers information to randomly-selected parents with children in primary school about their children's "academic performance" (which hereafter refers to performance on achievement tests administered by schools over the previous term). ${ }^{3}$ The information is delivered verbally and in a clear manner. I measure the effect of the information on parents' beliefs, and on a broad range of their investments and decisions, including both a series of real-stakes investment options and decisions presented to parents through the experiment ("experimental outcomes"), and more traditional endline outcomes such as enrollment and attendance in school ("non-experimental outcomes"). The analysis proceeds as follows.

I use baseline beliefs data to establish my first finding: that parents' beliefs are inaccurate. On average, parents' beliefs about academic performance diverge from true performance by more than one standard deviation of the performance distribution. When comparing two of their children, one third of parents are mistaken about which child is higher-performing.

I next combine information on believed performance, true performance, and investment decisions to test whether inaccurate beliefs affect parents' decisions. I establish my second finding - that, at baseline, parents base important decisions on their inaccurate beliefs - by demonstrating that, in the control group, the relationship between believed performance and investments is stronger than the relationship between true performance and investments. I then show my third finding - that the information intervention alleviates knowledge barriers - by showing that, in the treatment group, the relationship between true performance and investments becomes stronger, increasing to resemble the relationship in the control group between believed performance and investment. This is because parents' beliefs become more closely aligned with true performance, and they adjust their investments accordingly. The analyses show that student performance is an important input into parents' decisions, but that parents are often quite wrong about performance, resulting in important investment "mistakes" (i.e., wedges between how parents would like to allocate their investments given their children's true academic performance, and how they allocate them in reality).

I establish two broad categories of investment mistakes. The first is misallocation in the level of investment across children, i.e., cases in which the total amount invested in each child is not what parents want given children's academic performance. I test for this using both enrollment in primary school, and an experimental outcome proxying for resources allocated towards secondary school. Providing information has impacts on both, causing reallocations towards higher-performing students in both cases. This suggests parents prefer

\footnotetext{
${ }^{3}$ As described in Section 3, the Ministry of Education in Malawi requires all schools to send report cards to parents; thus, academic performance information should in theory be freely available in this context.
} 
to allocate more years of schooling to their higher performers. This analysis clearly shows that information frictions affect investments; the implications for welfare then depend on whether there are other interacting market frictions, including whether parents are correct about the education production function, which I discuss later in the paper.

The second category of mistake I uncover is in the types of investment chosen for a given child, i.e., failures to tailor the specific input mix correctly to a child's academic level - such as purchasing an advanced textbook for a low-performing child when the remedial textbook would have benefited her more. Here I use several experimental outcomes, such as demand for books designed for students of different performance levels. The prediction is that returns will be higher if the level of the selected book matches the level of the child's performance, and I find that providing information triples the closeness of the match. These types of parental decisions are now more relevant than ever in developing countries, since the use of supplementary inputs is growing rapidly (Paviot et al., 2008).

Finally, I provide evidence on a link between poverty and information barriers, showing that poorer, less-educated parents have less accurate baseline beliefs than richer parents, and that they adjust their beliefs and certain investments more in response to information.

This paper contributes to our understanding of how information frictions affect decisions. A large literature shows that providing information to households affects decisionmaking across many domains. ${ }^{4}$ However these interventions have primarily delivered information that one might not expect households to know, even richer or well-informed households. Some papers provide information that is difficult or sometimes impossible to obtain, such as the (normally unobservable) economic returns to an activity (e.g., Jensen (2010)), or statistics that require another entity's private information, such as school-average student performance or normally-unreleased data on student effort in school (Andrabi et al., 2016; Bergman, 2016). Others deliver information that is in principle available but requires non-trivial effort to obtain, such as personalized information about the cost of health plans or about the EITC schedule (Chetty and Saez, 2009; Kling et al., 2011). In contrast, this paper examines information that is seemingly readily available, showing that it is still not incorporated into the decisions made by the poor. This is important not just because it demonstrates a more surprising failure of optimization, but also because it provides evidence of a channel through which the poor might remain poor: frictions that prevent them from using information that seems readily available to all, but that only the rich can leverage.

This paper also contributes to the literature on information frictions in education. This literature has focused on misinformation about aggregate factors, such as the population-

\footnotetext{
${ }^{4}$ e.g. Liebman and Luttmer (2015); Kling et al. (2011); Bhargava and Manoli (2015); Duflo and Saez (2000); Dupas (2011); Fitzsimons et al. (2016); Jamison et al. (2013); Beshears et al. (2015)
} 
average returns to education, school quality, or other features of the education system, ${ }^{5}$ thus abstracting away from the fact that correct individual education decisions (such as whether to go to college, or whether to invest in a remedial textbook) vary across individuals. Here, I shift focus from aggregates to the heterogeneity within the population, providing to my knowledge the first evidence using exogenous variation in beliefs to establish a causal link between misinformation about individual-level characteristics and investment decisions. ${ }^{6}$

The paper proceeds as follows. Section 2 motivates the empirical approach. Section 3 describes the context and experimental design. Section 4 presents the results, and Section 5 concludes.

\section{Empirical approach for detecting mistakes}

How can one test whether inaccurate beliefs cause parents to make investment mistakes? I present a simple framework in which inaccurate beliefs cause mistakes and use it to generate empirical predictions. I then discuss how to use an experiment to test the predictions.

A parent is choosing investments in her children's schooling. Loosely speaking, she chooses both the level of spending on each child, as well as the specific type of educational resources for each child - for example, what difficulty level of textbook or tutoring to choose. Suppose we have data on one of these choices; denote parent $i$ 's choice as $s_{i}$. Parent $i$ chooses $s_{i}$ to maximize household utility subject to a budget constraint. Household utility depends on the return to choice $s_{i}$, as defined through the perceived production function for $s_{i}$ (i.e., the function mapping $s_{i}$ to its economic return). A key assumption - which can later be tested in the data - is that the perceived return to each $s_{i}$ depends on a measure of parent $i$ 's children's baseline academic performance, denoted by $a_{i}$, and that as a result, the utility-maximizing choice of $s_{i}$ varies with performance: $s_{i}=s^{*}\left(a_{i}\right)$, with $\frac{\partial s^{*}}{\partial a} \neq 0 .{ }^{7} \mathrm{I}$ call $s^{*}\left(a_{i}\right)$ the "preferred investment function." Much of the analysis centers around its derivative $\left(\frac{\partial s^{*}}{\partial a}\right)$, which may vary by investment, since the perceived production function can vary across investments. For example, if parents maximize returns and the investment is a perceived substitute with performance (i.e., a higher-return investment for a lower-performing child), $\frac{\partial s^{*}}{\partial a} \leq 0$; if it is a perceived complement, $\frac{\partial s^{*}}{\partial a} \geq 0 .{ }^{8} \mathrm{I}$ discuss the predictions for $\frac{\partial s^{*}}{\partial a}$ for each investment as I

\footnotetext{
${ }^{5}$ See for example: Jensen (2010); Nguyen (2008); Andrabi et al. (2016); Bettinger et al. (2012); Dinkelman and Martínez A (2014); Hoxby and Turner (2013); Wiswall and Zafar (2015).

${ }^{6}$ This builds on prior studies that use observational data to show that students' beliefs about their own abilities predict their decisions, such as college major choice or college dropout (Chevalier et al., 2009; Arcidiacono et al., 2012; Stinebrickner and Stinebrickner, 2012, 2014). My findings also complement a recent information experiment by Bobba and Frisancho (2016) that tests predictions about the differential roles of the mean and variance of beliefs on educational decisions.

${ }^{7}$ Note that we take $a_{i}$ to be a baseline measure which affects the returns to the investment; it is an input to the efficacy of $s_{i}$, not an outcome affected by $s_{i}$.

${ }^{8}$ If parents care not just about maximizing returns but also about equality between their children, then
} 
proceed through the analysis.

Assume the parent does not know true performance $a_{i}$. Instead, she has a distribution of beliefs about $a_{i}$ described by the individual-specific beliefs distribution $f\left(\alpha_{i}, \sigma_{i}^{2}\right)$, where both her mean beliefs $\left(\alpha_{i}\right)$ and the variance/uncertainty of her beliefs $\left(\sigma_{i}^{2}\right)$ may be correlated with $a_{i}$. She thus chooses $s_{i}$ to maximize expected utility taken over $f\left(\alpha_{i}, \sigma_{i}^{2}\right)$. Under many models, the uncertainty of her beliefs $\sigma_{i}^{2}$ would not affect her choice of $s_{i}$, and so for expositional simplicity, I first restrict attention to that case before generalizing below. ${ }^{9}$ In that case, parent $i$ 's chosen investment equals $s^{*}\left(\alpha_{i}\right)$; if parent $i$ 's mean beliefs are inaccurate $\left(\alpha_{i} \neq a_{i}\right)$, then this choice diverges from the utility-maximizing choice $\left(s^{*}\left(\alpha_{i}\right) \neq s^{*}\left(a_{i}\right)\right)$, a "mistake" which causes her utility to be inefficiently low.

If we have data on $\alpha, a$, and $s$ from a sample of parents investing as described above, what empirical patterns would suggest that parents are making mistakes? Mistakes stem from the fact that each individual's chosen investment $s$ does not vary with $a$ according to the preferred function $s^{*}(\cdot)$. Defining the actual investment function as the conditional expectation - taken across individuals - of investments chosen as a function of true performance, $\tilde{s}(a):=E(s \mid a)$, we thus want to test for a divergence between $\tilde{s}(\cdot)$ and the preferred function $s^{*}(\cdot)$. To empirically estimate $\tilde{s}(\cdot)$, one can (nonparametrically or parametrically) regress investments on true performance $a$; to estimate $s^{*}(\cdot)$, one can regress investments on (mean) beliefs, $\alpha$.

The form of the divergence between $\tilde{s}(\cdot)$ and $s^{*}(\cdot)$ depends on the joint distribution of $\alpha$ and $a$. In most beliefs data, including the data used in this paper, belief inaccuracies cause mean beliefs to be "attenuated" relative to true performance, i.e., to have a slope less than 1 if plotted on true performance (Figure $1(\mathrm{a})) \cdot{ }^{10}$ Writing the OLS formula for the slope of $\alpha$ on $a$ as $\operatorname{corr}(\alpha, a) \frac{S D(\alpha)}{S D(a)}$, one can see that, if the variance of $a$ and $\alpha$ are similar, a sufficient condition for attenuation of $\alpha$ on $a$ is that $a$ and $\alpha$ are positively but imperfectly correlated. The lower the correlation between $a$ and $\alpha$, the more attenuated the slope. This attenuation in beliefs then causes $\tilde{s}(\cdot)$ to have a flatter slope than $s^{*}(\cdot) \cdot{ }^{11}$ See Appendix C.1.1 for proof. ${ }^{12}$ The intuition is that parents choose investments based on their (inaccurate) beliefs; thus investments are steeply sloped with beliefs, as depicted in Figure 1(b) for the case where $\frac{\partial s^{*}}{\partial a}>0$. But, because parents' beliefs are inaccurate and attenuated,

the preferred investment function will also depend on parental preferences.

${ }^{9}$ This would hold if, for example, a parent's expected utility problem minimizes a quadratic loss function between the chosen $s$ and $s^{*}(a)$.

${ }^{10}$ For example, this could be microfounded with a Bayesian updating model where parents' prior beliefs are the population-average $a$, and each parent $i$ receives an imperfect signal of $a_{i}$.

${ }^{11}$ This attenuation can be seen as analogous to the attenuation bias caused by classical measurement error, but in order to make that analogy, one needs to think of beliefs as the correctly measured regressor and true ability as the mismeasured regressor. This is because the data generating process for $s_{i}$ depends on beliefs.

${ }^{12}$ This assumes $s^{*}(\cdot)$ is monotonic in $a$, i.e., that a given investment is always either a substitute or complement with $a$, but does not switch between substitute and complement for different ranges of $a$. 
if we look at children who are truly at the top of the distribution, many of their parents think they are below the top, and so on average choose inputs appropriate for lower-performing children. Analogously, many parents of children at the bottom of the distribution choose inputs appropriate for higher-performing children. This causes the slope of $\tilde{s}(\cdot)$ to be more attenuated (i.e., flatter) than the preferred slope (Figure 1(c)), and decreases welfare. More broadly, for any distributions of $a$ and $\alpha$, the prediction to test is:

Prediction 1. Inaccurate beliefs can cause the slope of the actual investment function to differ from the slope of the preferred investment function.

Estimation: It is difficult to empirically estimate the difference between the slopes of $\tilde{s}(\cdot)$ and $s^{*}(\cdot)$ because neither regression line is causal. Assume parents invest according to the model above plus an error term $\varepsilon$ that reflects all other determinants of investment: $s_{i}=s^{*}\left(\alpha_{i}\right)+\varepsilon_{i}$. The error term could represent either a measure unrelated to ability, such as parental valuation of education, or a measure of academic ability other than recent academic performance, such as perceived child IQ or a longer-term academic performance measure. Consider comparing the slope estimated from regressing investments on $\alpha$ to the slope estimated from regressing investments on $a$. The estimated slopes could differ from the true causal slopes as a result of omitted variable bias (OVB) from the correlations between $\varepsilon$, and $\alpha$ or $a$. In particular, if $\alpha$ and $a$ have different correlations with $\varepsilon$, then the slopes of the estimated lines may differ, but only due to OVB, not due to parents making mistakes.

We can use an experiment to overcome this estimation challenge. Consider an information intervention that tells parents true performance $a$ and changes their mean beliefs to equal $a$. If attenuation simply resulted from parents allocating $s$ based on some measure other than my performance measure $a$ (i.e., if attenuation simply resulted from OVB and not parental mistakes), then parents' investments would not change. If instead attenuation were the result of parents' inaccurate beliefs about $a$ causing them to make mistakes, then providing information on $a$ would allow parents to correct their baseline mistakes and choose their preferred investment $s^{*}(a)$, i.e., to invest along the preferred investment function:

Prediction 2. If inaccurate beliefs cause parents to make investment mistakes at baseline, then information can change the slope of the actual investment function. In the case of baseline attenuation, the slope will increase.

See Appendix C.1.2 for proof. An increase in the slope of the actual investment function as a result of providing information on $a$ thus shows us that parents' baseline decisions were not optimal from their own perspective. Note that moving to a statement about welfare would be more complex, relying, for example, on whether the perceived production function is correct; I discuss this in detail later in the paper. Note also that the predictions and empirical test 
above focus on information's impact on the slope of investments, not the average treatment effect (ATE) of information, since ATE tend to understate information distortions. ${ }^{13}$

Uncertainty: The earlier statement that a parent with mean beliefs $\alpha_{i}$ would choose inputs $s^{*}\left(\alpha_{i}\right)$ depends on the assumption that the utility-maximizing choice does not depend on beliefs uncertainty, $\sigma_{i}^{2}$. While this would be the case in some settings (e.g., if parents minimize a quadratic loss function), in others, having higher uncertainty could cause utilitymaximizing investments to diverge from $s^{*}\left(\alpha_{i}\right)$, and in particular, to become a function with a slope that is flatter in mean beliefs $\alpha_{i}$. This is because higher $\sigma_{i}^{2}$ may cause a parent to hesitate to make her investments depend as strongly on her mean beliefs. See Appendix C.2 for a framework yielding this prediction. This attenuation in the slope of investments on $\alpha$ would then further attenuate the slope of investments on $a$ relative to the case where there is perfect information about $a$. Thus, one can think of uncertainty in beliefs as a second channel for baseline attenuation in the slope of investments on $a$, which I later test for empirically.

\section{Context and experimental design}

The setting for the experiment is Malawi. Overall, the education system in Malawi is similar to the systems in many countries in both sub-Saharan Africa and elsewhere, in terms of the information given to parents as well as the overall structure. Primary school in Malawi covers grades 1-8. Although it has technically been free since 1994, it does involve expenditures. Parents in the study sample spent an average of 1,750 Malawi Kwacha (MWK) annually per child, roughly 10.6 USD or $1 \%$ of annual household income. The main expenditures are uniforms (33\% of total), informal but required school fees (22\%), and supplemental investments such as school supplies, tutoring, and books (45\%). The access rate to the first grade of primary school is above $95 \%$, but dropouts are common in primary school. Sources vary, but all suggest the completion rate (conditional on enrolling) is less than $60 \%$ (World Bank, 2010). Secondary school, covering grades 9-12, is not free, costing significantly more than primary school. Many children do not attend because of the high fees; annual fees for government secondary schools range from 5,000 - 10,000 MWK per year (30 - 60 USD, over 4 times the median primary-school expenditures in the sample) (World Bank, 2010). Uniforms and supplementary supplies are additional expenses. Secondary slots are also limited, with admissions governed by an achievement test administered at the end of primary school.

Similar to many other countries, schools are required to send report cards home each term with achievement test scores. The reports vary by school, but all are required to include average absolute test scores, and the corresponding grade on the standard Malawian grading

\footnotetext{
${ }^{13}$ For example, if beliefs are inaccurate at the individual level but the population-level mean is correct, and investments are linear in performance, then parents might make mistakes but there would be no ATE.
} 
scale of 1-4. (Online App. H contains an example from the study sample.) However, the official report cards are often hard for parents to understand, or do not reach them. According to baseline survey data, $64 \%$ of parents state that they do not know their child's performance from the last report; the main stated reasons are that the parents (a) were unable to read or understand the report, or (b) did not receive it in the first place. Students are supposed to deliver the reports, so children could either lose or choose not to deliver them: parents of students who performed badly are much less likely to receive the report. In addition, among the parents who think they know their children's performance, anecdotally, some do not. For example, some misunderstand the grading scale (e.g., think a "1" is the highest grade when in fact it is the lowest).

\subsection{Experimental design}

The experiment delivers academic performance information to randomly selected parents and measures the effects on educational investments and decisions. Although the school report cards should ostensibly already deliver this information, as described above, the report card system does not succeed in conveying the information; the experiment presents the information more clearly. To fit the framework presented in Section 2, the experiment should provide information about the individual-level trait on which parents' educational investments depend. According to qualitative interviews, parents in Malawi think academic performance (i.e., scores on school-administered exams) is the most important determinant of both their investments and the returns to educational investments. If parents were wrong about the education production function, a second objective relevant for a scale-up would be to use the trait most correlated with actual individual-level returns. Academic performance likely also meets this second objective: It determines progression through school and selection into secondary school, thereby almost surely affecting the returns to investment. "Innate" ability is another possible determinant of returns, but, as has been extensively documented, it is difficult to measure "innate" ability; any measure would represent some combination of innate ability and past inputs. (See Section 4.5 for further discussion.)

Sample selection: The study worked with 39 schools in two districts (Machinga and Balaka) in Malawi. Schools were selected randomly from the universe of primary schools, oversampling schools with high and low expected levels of parent education to increase heterogeneity in parent education within the sample. The study team first conducted a census at schools, mapping the sibling structures for all students in grades 2-6, which were chosen because they span most of primary school. Since one of the outcomes to be examined is inter-sibling tradeoffs, multiple-sibling households were used as the sampling frame (fewer than $3 \%$ of households in Malawi with children have only one child). The team also gathered

achievement test data from the most recent term (term 2 of the 2011-2012 school year) for 
use in the intervention.

Based on the test score and sibling data, a sample of 3,451 households with at least two children enrolled in grades 2-6 with test score data was drawn. For households with more than two children, two were randomly selected. Because one inclusion criterion was that children needed test score data, students who have the highest absence rates (and whose parents might have the largest information problems) are under-represented in my sample.

Randomization: I randomly assigned half the households in the sample to a treatment group that received information about their children's test scores, and half to a control group, which did not. ${ }^{14}$ The randomization was stratified on a test score measure (between-sibling score gap), and a proxy for parent education (the estimated literacy rate in the household's village), since one ex ante goal was to look at heterogeneity by parent education.

Eligibility interviews: Sample selection and randomization were based on data gathered from students at school and on school administrative data. Household eligibility (i.e., whether both siblings lived in the household and were still enrolled in school) was then verified through an eligibility questionnaire with parents. Among the 3,451 sampled households, $21 \%$ of households were found to be ineligible during the parent interviews, leaving a sample of 2,716 eligible households. Of the 2,716 sampled and eligible households, $97 \%$ (2,634 households) were located at their homes, available, and consented to participate in the baseline survey. Thus, the final experimental sample comprises 5,268 parent-child pairs. Both eligibility and baseline survey completion are unrelated to treatment assignment.

Baseline survey visit: Surveyors visited all sampled households and asked to speak with the parent who is the primary decision-maker about education. ${ }^{15}$ Surveyors then conducted a baseline survey, which included a module on education spending and beliefs about children's test scores. While eliciting baseline beliefs about test scores, surveyors explained the grading scale used by schools to parents; they also reviewed a sample report card with the same format as those later delivered to the treatment group. This was done to aid the elicitation of beliefs and to hold knowledge of the grading scale and report card format constant across treatment groups. After the survey, during the same visit, surveyors conducted the information intervention for the treatment group.

\section{Information intervention and report cards (Treatment group only): Surveyors}

\footnotetext{
${ }^{14}$ Half the treatment group was also assigned to receive an add-on intervention designed to test a hypothesis intended for study in separate work: that providing more detailed information would increase parental engagement, as measured through non-monetary and monetary investments. This group received additional skills information (e.g., whether their child could add 3-digit numbers, see Online Appendix I for sample). In this paper, I ignore this add-on treatment and pool the treatment households. I do not find that this treatment had an effect on the pre-specified outcomes.

${ }^{15}$ If that parent was unavailable, the surveyor spoke with the second parent if that parent was present and knowledgeable about educational decisions. If not, the surveyor returned later.
} 
walked parents in the treatment group through two report cards (one per child) describing the academic performance of their children. The order was randomized. The reports showed children's performance on all tests administered in the most recent school term, specifically: the percent score (an absolute measure), the corresponding grade on the Malawian grading scale, and the within-class percentile ranking (see Online Appendix J for more details). The statistics were listed for the three subjects that Malawian educators deem most important - math, English, and Chichewa, the local language - and for "overall" (the average of the three). The report card also showed the number of individual tests included in the averages; the sample average is 4.5 tests. The correlation between students' scores on the different individual tests is roughly 0.8 for overall performance, and $0.6-0.7$ within subjects.

A sample report card is presented in Appendix B. The format was chosen based on a series of focus groups, with the primary selection criterion being how well uneducated parents could understand it. Surveyors, who were trained on how to explain the information clearly, walked treatment parents through every number on the report cards.

\subsection{Data and outcomes}

The analysis uses several data sources, including data from surveys with parents and administrative data from schools. Online Appendix J.1 shows the survey questions that measured beliefs and the experimental outcomes, and the scripts for the information intervention.

(1) Baseline survey data: The baseline survey was rolled out immediately after term 2 of the school year ended in March 2012, and ran from April to June of 2012. The survey included modules on demographics, education spending, and the perceived returns to education. Mean beliefs about academic performance were measured by asking parents about the same performance metrics that were later delivered in the intervention report cards - average scores and percentile rankings on the term 2 school exams in math, English, Chichewa, and overall. We used the same measure later used in the intervention so that any gaps between believed and true performance represent belief inaccuracies, not differences between measures. Beliefs uncertainty was measured by asking parents to distribute tokens across bins representing score ranges (e.g., 0-20).

(2) First endline survey - Endline beliefs and experimental outcomes: This survey was conducted immediately after the baseline survey and information intervention; see Figure 2 for the data collection timeline. This was done for budgetary reasons, but does have the advantage that the outcomes were measured before parents had a chance to speak with others, allowing the outcomes to more cleanly reflect parents' preferences, as opposed to the preferences of the people they talk to, including their children. Recall that there are two main categories of investment outcomes: (i) a series of real-stakes investment options and decisions presented to parents through the experiment ("experimental outcomes"); and (ii) 
more traditional endline outcomes measured during the year after the intervention, such as enrollment ("non-experimental" or longer-term outcomes). This survey measured the first category, which is described in more detail in Section 3.2.1 below, as well as endline beliefs. When measuring endline beliefs, because I wish to assess whether information affects the beliefs underlying parents' behavior, I want to know both whether (a) parents understood and believed the information presented in the intervention, and (b) the information is relevant for their decisions going forward. As a result, surveyors asked parents what score they thought their child would receive if he took an exam that same day. Asking about the previous-term scores as done in the baseline survey would only have measured (a), since those exams happened in the past; asking about a (hypothetical) same-day measure allows us to also assess (b). I refer to these beliefs as "endline beliefs." Beliefs uncertainty was not measured at endline due to budget constraints.

(3) Non-experimental (longer-term) outcomes: I also collected two types of data in the year following the intervention: (i) a second endline survey of parents 1 year after the intervention (June-July 2013), which I use to examine treatment effects on dropouts and expenditures, and (ii) administrative data on attendance gathered roughly 1 month after the intervention (July 2012). These outcomes allow me to establish the policy relevance of the findings. For the 1-year second endline data collection, given the very limited budget available, I focused on outcomes where (a) I expected results, and (b) data collection costs were lower. I thus focused on dropouts and expenditures, rather than academic performance. Dropouts and expenditures are parental decisions that are easy to adjust, whereas academic performance reflects many other factors. There was sufficient budget to include roughly 900 households in the second endline survey sample. Of the households selected for the sample, 98\% (893) were successfully surveyed, balanced across treatment group. The administrative attendance data was gathered by giving schools templates to record the data for the month following the intervention, and was collected from $35 \%$ of the sample. During the attendance data collection, we were able to collect data on endline exams for $9 \%$ of the sample, which allows me to validate the accuracy of the baseline academic performance measure, but does not give sufficient statistical power to look at treatment effects. See Online Appendix J.2 for more detail on the sample and data for the non-experimental outcomes.

\subsubsection{Experimental outcomes}

During the first endline survey, surveyors presented parents with three real-stakes investment decisions (the "experimental outcomes"). While the non-experimental outcomes are preferable from a policy-relevance perspective, these experimental outcomes have several advantages. The primary advantage is that they enable me to include outcomes that are designed to have clear predictions for how the efficient investment depends on student 
performance, allowing for a clean test of whether misinformation causes mistakes. They also allow me to include outcomes where the "preferred investment function" is homogeneous by parental education, allowing me to cleanly test for whom inaccurate beliefs matter more. Finally, they are very precise, allowing for detailed heterogeneity analysis.

The outcomes include a combination of monetary investments involving cash outlays, and choices between free options. The latter allow us to abstract away from credit constraints, which is useful for heterogeneity analysis as it enables cross-household comparisons that are not confounded by household wealth. The outcomes also incorporate both smaller investments that primarily assess effects on the types of investments parents choose, i.e., whether they tailor the input mix correctly to their children's needs, and a larger outcome designed to detect treatment effects on the level of investment across children.

Outcomes capturing the type of investment: The first decision presented to parents is a choice among free workbooks with different difficulty levels. We gave parents four free books - an English and a math book for each of their two children. For each book, parents were allowed to choose between three levels of difficulty: beginner, average, or advanced. The obvious prediction is that book difficulty choice will increase in perceived performance.

The second investment is the willingness to pay (WTP) for subject-specific remedial textbooks in math and English. WTP was evaluated using a Becker-DeGroot-Marschak (BDM) methodology, which gives respondents an incentive to report truthfully (see Online Appendix $\mathrm{K}$ for description). The elicitation was real-stakes, with parents paying out-ofpocket for the textbooks using their own money, and the maximum price on the price list equal to the full market price. The average WTP for a book was substantial: 324 MWK (2 USD), or roughly $20 \%$ of mean annual per-child educational expenditures. We use remedial textbooks (textbooks perceived by teachers as substitutes with performance). Thus, the prediction is that WTP will be higher for the subject in which parents think their child is doing worse; this was an ex ante prediction, later confirmed by baseline survey questions showing that $95 \%$ of parents believe the textbooks are substitutes with performance.

Both the textbooks and free workbooks have clear predictions for parents' beliefs about the "right choice" (i.e., the perceived production function). An additional advantage is that both have clear predictions for the actual right choice and true production function. For example, the advanced workbook was designed specifically to be better for the higher performers in the sample. This enables a stronger argument that parental mistakes due to misinformation about child performance would lower actual (not just perceived) returns.

Outcome capturing the level of investment across children: Secondary schooling is the first high-cost educational investment in Malawi. Few parents in the sample could afford these fees for all of their children; many cannot for even a single child. My third 
investment introduces a short-run, real-stakes proxy for secondary schooling. We conduct a lottery, in which the prize is four years of government secondary school fees for one child in every 100 households, worth roughly 120 - 240 USD at the time of the experiment. Parents were given nine tickets for the lottery and were asked to allocate the tickets across their two children. There are many "binary" choices in education where credit-constrained parents must choose between a lumpy investment in one child or the other, for example if parents can only afford to send one child to secondary school or college. The lottery ticket allocation - and in particular, which child the parent allocates more tickets to - was designed to proxy for these types of decisions. ${ }^{16}$

There are two main channels through which academic performance would affect the expected return of a lottery ticket. First, through the earnings return to secondary school: $95 \%$ (78\%) of parents believe that secondary school increases the earnings of higher-performing students weakly (strictly) more than the earnings of lower-performing students, and, on average, parents perceive the earnings increase to be $90 \%$ higher for a hypothetical child in the top decile of performance than for one in the bottom decile. Second, since admissions is governed by performance on a standardized achievement test, the probability of admission to secondary school increases with performance - a fact that $98 \%$ of parents are aware of. Thus, the (perceived) expected value of the fees paid and the probability of attending increase with performance. Taking both channels together, a back-of-the-envelope calculation based on parents' beliefs suggests that the perceived return is over $300 \%$ higher for students in the top vs. bottom performance decile. ${ }^{17}$ Thus the prediction is that parents will allocate more lottery tickets to higher-performing children.

\subsection{Summary statistics and balance}

Table 1 presents summary statistics and tests for balance across the treatment and control groups. $77 \%$ of respondents are female, and $92 \%$ are the primary education decision maker in the household. Average levels of parental education are low, at 4.7 years. Households are large, with an average of 5 children. Sampled children were 12 years old on average, primarily aged 8 to 16 , with $51 \%$ female. To test balance, I regress each variable on a dummy for being in the treatment group. The differences between the treatment and control groups are never large, with a joint test of equality failing to reject the null that all are 0 ( $\mathrm{p}$-value $0.67)$ and only one of the 39 variables statistically significant at the $5 \%$ level: baseline math

\footnotetext{
${ }^{16}$ Although a single ticket could have also accomplished this goal, I used multiple tickets to increase the power to detect small shifts and to allow me to make use of this lottery in a separate paper studying inequality aversion. As expected, most parents $(74 \%)$ split their nine tickets as evenly as possible, consistent with an aversion to inequality between their children. The analysis thus reduces in most cases to analyzing which child the parents give their ninth ticket to, which proxies for the child they would choose in a binary choice.

${ }^{17}$ See Online Appendix L for calculation.
} 
scores. To ensure this imbalance does not affect the results, all regressions control for an academic performance measure, although the results are robust to omitting this control.

\section{Empirical results}

I begin by showing that parents have inaccurate beliefs about their children's academic performance. I then demonstrate, using first the experimental and then the non-experimental outcomes, that their belief inaccuracies cause them to make mistakes when making decisions. Finally, I provide evidence linking information frictions with poverty, and discuss the implications of information frictions for welfare and the average level of investment in education.

\subsection{Beliefs}

Result 1A: Parents' beliefs about academic performance appear to be inaccurate.

Data from the baseline survey can be used to assess the accuracy of parents' beliefs about their children's "academic performance," i.e., scores on school-administered exams the prior term. Figure 3(a) presents the average of the absolute value of the gap between parents' mean beliefs about their children's academic performance and their children's true academic performance. Scores are absolute percentages, expressed on a scale from 0 to $100 .{ }^{18}$ The graph shows the treatment and control groups separately to demonstrate baseline balance.

The average gap is large: 20 points, or 1.2 standard deviations of the performance distribution for overall performance. Table 1, Panel F shows that mean beliefs about individual subjects like math, between-subject performance (math vs. English), and the between-sibling gap are also inaccurate. Beliefs about the between-sibling gap diverge from the true gap by 1.1 std. dev. on average, with $31 \%$ of parents wrong about which of their own children is higher-scoring. While parents overestimate on average, $21 \%$ of parents do not.

As described in Section 2, these belief inaccuracies should cause mean beliefs to not move 1-to-1 with true scores and instead to be an attenuated function of true scores. Figure 3(b) substantiates this for overall performance with a local linear regression of mean beliefs on true performance: the slope is visually less than 1 . The attenuation in the slope captures the fact that the correlations between believed and true performance are low: 0.3 for overall performance, as depicted in the graph, and 0.2-0.3 for performance in the individual subjects like math. Since these tests determine progression through school, these inaccuracies are likely relevant for a broad range of investments.

\footnotetext{
18 The online appendix shows that the main results are robust to using relative performance (withinclass percentiles) instead of absolute performance. (Tables G.1, G.2, and G.3.) In my sample, absolute and relative performance are highly correlated (0.8). Rogers and Feller (2016) compare the effects of relative versus absolute information about student absence rates from school; such a comparison was not a goal of this study. That being said, Online Appendix G.18 shows results when both measures are analyzed simultaneously, and parents seem to respond more to absolute than to relative information. Online Appendix J.4 discusses this in more detail, as well as explaining the other reasons that the analysis uses absolute performance.
} 
One natural question is whether these "inaccuracies" in beliefs simply reflect noise in the performance measure. The data suggest otherwise. The correlation between tests taken during the term is 0.8 for overall performance, and 0.6-0.7 within subjects, which suggest high test reliability; these are notably higher than the correlations between parents' beliefs and the term-average scores (0.2-0.3). I also have data on future test scores for a small subset of the sample which shows that baseline test scores are nine times more predictive of future test scores than parents' baseline beliefs are. ${ }^{19}$ Moreover, we can use the experiment itself to provide more evidence on this issue: If providing information to parents causes them to update their beliefs, it suggests that parents themselves believe that there is additional meaningful content in the information that was not reflected in their baseline beliefs.

\section{Result 1B: Providing information affects beliefs.}

I now ask whether information changes beliefs and decreases attenuation by looking at the impact of information on mean beliefs measured at endline. Recall that, unlike beliefs measured at baseline, the beliefs question asked at endline was not asking about last-term test scores; instead, it asked how well parents thought their child would do on a hypothetical test taken that same day. The prediction is thus that providing information should decrease the gap between parents' endline beliefs and their child's last-term scores, as their posterior beliefs move in the direction of the signal; the gap however should not fall to 0, unless parents place no weight on other factors (e.g., their assessment of their child's recent progress). Figure 3(c) graphs the absolute value of the gap between true baseline (last-term) performance and endline beliefs, separately by treatment group. Consistent with Bayesian updating, information cuts the gap nearly in half. Figure 3(d) shows that attenuation correspondingly decreases: the slope of endline beliefs on true baseline scores is over twice as steep for the treatment group as for the control group.

I formally test whether information increases the slope of endline beliefs by running the following regression:

$$
y_{i j}=c_{0}+c_{1} A_{i j} \times \text { Treat }_{i}+c_{2} A_{i j}+c_{3} \text { Treat }_{i}+c_{4}^{\prime} X_{i j}+\varepsilon_{i j}
$$

where $i$ indexes households, $j$ indexes siblings, $y_{i j}$ is the parent's endline beliefs about overall academic performance, $A_{i j}$ is baseline overall academic performance, Treat $t_{i}$ is an indicator for being assigned to the treatment group, and $X_{i j}$ is a vector of control variables. ${ }^{20}$ Standard

\footnotetext{
${ }^{19}$ See Online App. Table G.4 for a regression using control group data: the coefficients on current test scores and beliefs are 0.74 and 0.08 , respectively. Misunderstanding the difficulty of the grading scale also does not drive the results: the patterns are similar for within-class percentile ranks (Online App. Table G.1).

${ }^{20}$ Results are robust to excluding the controls (see Online Appendix Tables G.5 and G.6). Controls include school fixed effects (FE), the between-child score gap, average parental years of education, child and parent gender, and grade FE. This includes all variables underlying the stratification but not the stratum FE
} 
errors are clustered at the household level. Table 2, col. (1) confirms the increase in slope $\left(c_{1}>0\right)$. Information thus has a statistically significant "first stage" effect on beliefs, allowing us to use the experiment to examine the effects of information and beliefs on investments.

\subsection{Results: Experimental outcomes}

I first examine the "experimental outcomes," i.e., the investment decisions presented to parents in the first endline survey, which allow me to cleanly document investment mistakes, before turning to the "non-experimental outcomes" to establish greater policy relevance. I begin by using data from the control group to provide motivating evidence of mistakes, and then present the information treatment effects.

\section{Result 2A: Control group parents attempt to tailor their investments to perfor- mance, but partly fail.}

Data from the control group can be used to study how baseline parental investments depend on parents' beliefs about performance. This can give us insight into parents' preferred investment function and the likely production function that they have in mind. We can then compare this with how investments vary with true performance. A divergence between the two relationships would suggest that inaccurate beliefs affect investments.

Figure 4 compares the preferred investment function (investments plotted against believed performance - the dashed lines) with the actual investment function (investments plotted against true performance - the solid lines). Note that the y-axes for both lines represent investments, but the x-axes differ. Both are locally linear regressions using control group data. I first interpret the preferred functions. I then compare them to the actual.

Panel (a) of Figure 4 presents the results for math and English workbook difficulty choices graphically. Recall that for each book, parents could choose from 3 different difficulty levels. The y-axis represents the chosen difficulty level, with the three different levels parametrized as $0 / 1 / 2$ for simplicity, but the results are robust to other parametrizations. ${ }^{21}$ I focus first on the dashed lines, which represents parents' preferred choice given their beliefs about their child's math or English score, represented by the x-axis. The obvious prediction is that book difficulty choice should increase in believed performance, and indeed, consistent with this prediction, the dashed lines for both English and math slope steeply upwards.

Panel (b) of Figure 4 presents similar results for the second investment, the willingness to pay (WTP) for subject-specific textbooks in math and English. Because the textbooks are remedial, the prediction is that WTP will be higher for the subject in which parents think their child is doing worse. The use of the between-subject WTP (math - English)

themselves; I pre-specified that I would not control for stratum FE because some strata are very small: $15 \%$ of observations would be lost if I included stratum FE. But, the results are robust to including stratum FE.

${ }^{21}$ See Online Appendix Tables G.7 and G.8 for robustness to an ordered probit specification. 
holds constant other factors such as the child's overall performance, which is advantageous for this test as it provides clean predictions. ${ }^{22}$

In Panel (b), as in Panel (a), the dashed lines are the preferred investment lines. The $\mathrm{x}$-axis shows beliefs about performance in English relative to math. The y-axis shows the $\log$ of WTP for the math textbook minus the log of WTP for the English textbook; ${ }^{23}$ for presentation purposes, English is flipped relative to math on the y-axis, so that the prediction is that the line will have a positive slope. The dashed line slopes steeply upwards, consistent with the prediction that WTP increases the further behind a child is in a given subject.

Panel (c) of Figure 4 shows the secondary school lottery ticket allocation results. The dashed line plots the difference in tickets allocated to the older versus the younger child in the pair, with the $\mathrm{x}$-axis the gap in perceived scores between the older and younger child. ${ }^{24}$ Consistent with the ex ante prediction that allocating more tickets to higher-performers yields higher returns, the line slopes upwards: Parents give more tickets to the child they think is higher-performing.

I now compare the slope of the preferred investment functions just discussed with the slopes of the actual investment functions, depicted by the solid lines in Figure 4. The solid lines have the same $\mathrm{y}$-axes as the dashed lines, but different $\mathrm{x}$-axes: Their $\mathrm{x}$-axes are true performance instead of believed performance. The prediction is that if parents base their investments on their inaccurate beliefs, then the slope of their investments on true performance will be attenuated relative to the slope on beliefs. And, in fact, the graphs show precisely this pattern: The slopes on true performance are only 15-40\% as large as the slopes on beliefs. This suggests that parents try to tailor their investments to performance, but that their inaccurate beliefs prevent them from doing so. Since returns depend on true performance, if parents knew that, say, their child had a math score of 80 , they would choose the highest difficulty book for him, but many parents do not know that and so fail to choose their preferred option. This evidence is suggestive, however, not causal; both beliefs and performance could be correlated with other factors that determine investments. An experiment, in contrast, can establish causality: I can test whether information undoes the attenuation. It is this I turn

\footnotetext{
${ }^{22}$ The ex ante plan was to analyze within-child, between-subject WTP, since surveys with teachers showed that teachers universally think that, within child, the remedial textbooks have higher returns in a subject in which the child is behind. In contrast, teachers have more mixed opinions about whether remedial textbooks have higher returns for a child who is behind in a subject relative to a child who is ahead. These mixed opinions reflect the fact that a child who is behind in one subject also has lower performance on average, and so might be less inclined to use a textbook, even a remedial one, since he/she may be more likely to drop out of school, etc. The within-child, between-subject comparison holds those factors constant.

${ }^{23}$ Only $6 \%$ of observations are 0 's, which I replace with the log of $10 \%$ of the lowest price list value, but the results are robust to using other values (e.g., 50\%), dropping the 0's, or using levels instead of logs.

${ }^{24}$ Since the lottery is a within-household allocation, to depict it graphically, we need to order the two children in some way. Parents identified age in focus groups as the second most important factor for investment (behind performance), so I order using age, but the graphs look similar with any order.
} 
to next.

\section{Result 2B: Information substantially increases the slope of investments}

I now use the information experiment to test whether information increases the slope of investments on actual performance. Figure 5 shows locally linear regressions of investments on true performance for the treatment group (dashed line) and control group (solid line). Both lines have true performance as the x-axis. Note that Figure 4 examined only the control group, and thus the solid lines in Figures 4 and 5 are identical, as they depict the same data.

The figures confirm that information frictions cause mistakes: For all three investments considered, the information treatment substantially increases the slope of the investment functions. I perform a formal test of the change in slope by estimating equation 1 using the experimental outcomes as the outcome variables, and using the relevant academic performance metric as $A_{i j}$ (e.g., math for math workbooks). The prediction is that the information treatment makes the slope steeper, so that $c_{1}>0$ (with $c_{1}$ the coefficient on $A_{i j} \times$ Treat $_{i}$ ). The key prediction regards $c_{1} ; c_{3}$, the coefficient on Treat $_{i}$, is not particularly meaningful as it is just driven by the scaling of the $A_{i j}$ variable, representing the treatment effect for those for whom $A_{i j}=0$ for the particular $A_{i j}$ measure used in that regression. For example, for the textbook regression, it is the treatment effect for those for whom math and English performance are the same (i.e., math - English $=0$ ).

Columns (2) through (5) of Table 2 present the results for the math and English workbook difficulty choices; the log of WTP for the math textbook minus the log of WTP for the English textbook; and the secondary school lottery tickets received. Since secondary school lottery tickets are inherently a within-household allocation (one child's allocation fully determines the other's), the lottery regression is estimated with a household fixed effect. Consistent with the graphical evidence, across all outcomes, $c_{1}$ is positive and statistically significant. The magnitudes are large: Comparing the coefficient on Score (slope in the control group) with the sum of the coefficients on Score and Treat $\times$ Score (slope in the treatment group), information causes investments to become 3-6 times more steeply aligned with performance across the various investments, i.e., the slopes increase by roughly 200-500\%. This suggests that parents were making substantial mistakes at baseline.

One question is whether demand effects play a role in the patterns seen here. Although demand effects should affect both treatment and control groups and should thus not directly account for the treatment effects, demand effects could cause all parents, treatment and control, to choose investments more closely tied to perceived academic performance (i.e., affect the slope of the preferred investment function). The use of real stakes for all investments, which is the standard approach to address demand effects, helps assuage this concern. Moreover, treatment effects on the longer-term outcomes can also mitigate the concern, since 
these outcomes should not be subject to demand effects. I analyze these outcomes next.

\subsection{Results: Non-experimental (longer-term) outcomes}

The above results demonstrate that inaccurate beliefs cause parents to make mistakes when allocating educational investments. An open question, however, is the relevance for decisions outside of the experimental environment. I next turn to longer-run, non-experimental outcomes to show that information frictions are also relevant for outcomes that map more directly to the policy outcomes of interest. However, the ex ante predictions for the preferred investment function are generally not as clear, ${ }^{25}$ and precision is lower.

\section{Result 3: Information affects the slope of non-experimental investments}

I again examine the effect of information on the slope of investments. Panel A of Table 3 presents estimations of equation 1, all using overall scores as the performance measure. To aid in interpretation, Panel B shows estimates using binary regressors for both performance and education, specifically: indicators for whether a student has above-median score and for whether a household has above-median parent education. I consider three outcomes: primary school enrollment (dropouts), attendance, and expenditures. Of the three, primary school enrollment, which likely proxies most closely for the overall level of investment, provides the cleanest test: Consistent with the literature, most parents believe additional years of schooling are more valuable for higher-performing children, whereas parental beliefs about the complementarity of expenditures or attendance with performance, as elicited in interviews, vary widely across parents. The literature on attendance and expenditures is also limited, and there is little reason to expect the production function to be the same as for years of schooling. For example, conditional on having a child enrolled in school, parents may need to invest more in their lower-performing children to keep them on track.

Column (1) shows the primary school enrollment results. Consistent with the fact that nearly all parents believe years of schooling are a complement with academic performance, information increases the slope of the investment function. High-performing students in the treatment group are more likely to be enrolled in school one year later, while low-performing students are less likely to be enrolled. The change in the slope in Panel A is significant at the $1 \%$ level. ${ }^{26}$ Panel $\mathrm{B}$ shows that the magnitudes are economically meaningful. Among

\footnotetext{
${ }^{25}$ It is also harder to use control group data to generate predictions for the production function parents have in mind; compared with the experimental outcomes, these outcomes have more omitted determinants, making the observational regressions harder to interpret. However, we can still use the information treatment effects themselves to infer the perceived complementarity/substitutability of the investments with performance.

${ }^{26}$ Many evaluations use self-reported enrollment as the outcome of interest (e.g., Bourguignon et al., 2003; Schultz, 2004), but Baird and Özler (2012) show that self-reported and school data do not always match. I have dropout data from $10 \%$ of the schools and, reassuringly, the coefficient on Treat $\times$ Score is the same regardless of the data source used, reflecting a high correlation between measures (0.5). Since the dependent variable mean is near 1, Online App. Table G.9 shows robustness to a probit specification.
} 
children whose parents found out they had above-median performance, dropout falls to nearly $0 \%$ (from a control group mean of $2 \%$ ), whereas it roughly doubles for those with below-median performance, increasing from $2 \%$ to about $4 \%$. These results highlight that information does not improve educational outcomes for all: it leads to reallocations, which can decrease investments for some. Since the literature suggests that schooling and ability are complements, these reallocations are consistent with an improvement in returns (Pitt et al., 1990; Aizer and Cunha, 2012). In contrast to the results for primary school enrollment, but perhaps to be expected given parents' heterogeneous beliefs regarding complementarity with performance, I find no significant effects for either expenditures or attendance. See Appendix D for results for two additional secondary outcomes.

\subsection{The link between information frictions and poverty}

I now provide evidence linking information frictions with socioeconomic status (SES) by testing for heterogeneity by a measure of SES: parental education. I use parental education both because it is the least noisy measure of SES in the data, and because limited education provides a potential channel for why low-SES parents are less able to access information.

\section{Result 4A: Less-educated parents have less accurate beliefs.}

Panel A of Table 4 presents the results of the following regression testing for heterogeneity in the attenuation of beliefs by parental education:

$$
\tilde{A_{i j}}=d_{0}+d_{1} A_{i j}+d_{2} A_{i j} \times E d u c_{i}+d_{3} E d u c_{i}+\varepsilon_{i j}
$$

where $\tilde{A_{i j}}$ is parent $i$ 's baseline beliefs about child $j$ 's academic performance, $A_{i j}$ is child $j$ 's academic performance, and $E d u c_{i}$ is household-average years of parental education. The prediction is $d_{2}>0$ : more-educated parents have less attenuated beliefs. The table shows that $d_{2}$ is strongly positive. The magnitudes of the estimates suggest that going from 2 to 7 household-average years of education (the $25 \mathrm{th}$ percentile to the 75 th percentile of the distribution) increases the slopes by roughly $25-55 \% .^{27}$

\section{Result 4B: The effects of information can be larger for less-educated parents.}

I now examine whether, in addition to having less accurate beliefs, less-educated parents also respond more to information. I first look at the effects on belief updating, shown in column 1 of Panel B of Table 4, which shows the results of estimating equation 1 fully

\footnotetext{
${ }^{27} \mathrm{An}$ alternate way to look at belief accuracy is to test whether the absolute value of the gap between beliefs and true scores is larger for less-educated parents. Appendix Table A.1 presents the results of this test with consistent results. Online Appendix Table G.2 shows robustness to other measures of parent education, as well as child performance. Online Appendix Table G.10 shows robustness to controlling for other variables and their interactions with score, including school fixed effects interacted with score.
} 
interacted with household-average years of parent education. The results show that lesseducated parents update their beliefs more than more-educated parents.

We may also wish to know whether this translates into "larger effects" on their decisions. Testing this is non-trivial, since it is difficult to define exactly what a "larger effect" is. In particular, the magnitude of a parent's response will depend on her preferred investment function, which in turn depends on her preferences and budget, both of which may vary with SES. Some preferred investment functions may be steeper for richer parents, others for poorer parents. To make an "apples to apples" comparison, then, it is useful to focus on the investments where the preferred investment function is as homogeneous as possible across parental education levels - and where thus the heterogeneity speaks directly to heterogeneity in the impact of information, since, if there were no gaps in the accuracy and uncertainty of parents' baseline beliefs, there would be no heterogeneity in the results by parental education. The choice of difficulty level of free workbooks is most likely to meet this criterion, and was expressly included in the design to provide homogeneity across education levels. ${ }^{28}$ Columns (2) and (3) display the results, showing that information has a larger effect for less-educated parents. At baseline, the workbook choices of above-median-education parents are roughly 90\% (30\%) more steeply sloped for math (English) than the choices of below-median-education parents (see positive coefficient on Score $\times$ Parent yrs of educ.); information fully closes the gap (see negative Treat $\times$ Score $\times$ Parent yrs of educ.). See Dizon-Ross (2018) to see the results for the other outcomes, where there is more potential for heterogeneity in the preferred investment function by parental education.

\subsection{Welfare and average treatment effects}

This experiment shows that providing information to parents affects their beliefs and decisions. This reveals that parents' decisions at baseline did not fully incorporate the information, and that parents themselves think the information makes them better off, i.e., that, according to their own (perceived) utility functions, information increases utility. Although establishing these findings was the key conceptual goal of the paper, one may also wonder about the broader welfare implications. Welfare conclusions are difficult, since any intervention that corrects one market imperfection can decrease welfare if there are multiple interacting market failures (the "theory of the second best"). Definitive welfare conclusions are thus beyond the scope of this paper. That said, I now provide some speculative discussion.

First, to draw conclusions about parents' welfare, we would need to know whether their

\footnotetext{
${ }^{28}$ Since the workbooks are free, the choice should not be confounded by wealth. Moreover, we expect parents to choose the workbook difficulty level most closely matching their beliefs about their child's performance, and there is no ex ante reason to expect heterogeneity in that behavior by parental education. This is corroborated by Online Appendix table G.11: regressions of workbook difficulty level on baseline beliefs in the control group show that there is no heterogeneity in that relationship by parent education.
} 
perceived education production function is correct, including how predictive the performance information is for the returns to investment. ${ }^{29}$ Reassuringly, in both developed and developing country contexts, there is evidence that grades are correlated with other measures of ability, and that grades and achievement tests may even be better predictors of life outcomes (e.g. wages) than standard measures of ability (Borghans et al. (2011); Sternberg et al. (2001); Borghans et al. (2016)). In addition, for the outcomes that proxy for years of schooling (i.e., primary school enrollment and the secondary school lottery), although there are no estimates of the production function in Malawi, estimates from other contexts suggest that years of schooling and other measures of ability are complements (Pitt et al., 1990; Aizer and Cunha, 2012). Moreover, there are reasons to expect that the complementarity might be greater in this setting: the education system in sub-saharan Africa is particularly oriented towards high performers (Duflo et al., 2011), and achievement tests determine progression through school and access to higher levels of schooling, thus mechanically linking them with returns. My finding that parents allocate more years of schooling to their higher performers suggests they believe this complementarity exists, and is therefore consistent with parents being correct about the production function, but more evidence would be needed for firm conclusions.

Second, to move to social welfare, we would also need to assess both the externalities of education and the social welfare function. Although no single summary statistic could fully summarize the welfare impacts, the conventional wisdom is that market imperfections (such as positive externalities of education) collectively cause the average level of education to be below the optimum. As a result, it might be concerning from a welfare perspective if providing information about academic performance caused the average level of investments to fall. Reassuringly, here, information does not appear to decrease the average level of investments, although the results are imprecise. Specifically, Panel A of Appendix Table A.2 presents the estimates of the average treatment effect (ATE) of information. I do not find any statistically significant ATE of information on the investments that could proxy for the overall level of investments: enrollment, expenditures, and attendance. ${ }^{30}$

One might be surprised by the absence of an ATE for enrollment. Parents on average overestimate their children at baseline, and, for enrollment, invest more in higher performers, suggesting that information might decrease enrollment. Appendix E describes several potential explanations for the lack of an ATE, one of which I find empirical support for: Parents respond more to information when the information is positive than when it is negative. This

\footnotetext{
${ }^{29}$ Note that this is much less of a concern when analyzing some of the experimental outcomes (e.g., the workbooks and remedial textbooks). These investments were designed to have clear predictions for increased returns, and, across the parental education spectrum, parents' reallocations align with the predictions.

${ }^{30}$ The workbooks and textbooks were designed specifically to look at the types of investment chosen, and thus their level does not proxy for overall spending. For completeness, however, these ATEs are also reported in Appendix Table A.2.
} 
is consistent with the findings of the motivated beliefs literature (Eil and Rao, 2011; Mobius and Rosenblat, 2014). See Appendix E and Table A.3 for the analysis and discussion.

\subsection{Mechanisms}

Results 1-4 clearly show that providing student performance information to parents affects their decisions. Are there any explanations for this besides the fact that information changes parents' beliefs about their children's academic performance? One potential alternative explanation is that information affects the salience of academic performance. However, assuming salience effects are uniform across the population, they should affect the investment level, not the slope, so would not be responsible for the effects seen here. ${ }^{31}$

A related question is whether information affects investments primarily by affecting the mean or the uncertainty of parents' beliefs distributions. I investigate this in Appendix F. The analyses suggest that the primary mechanism for information's effects on the types of investments chosen (e.g., difficulty levels of workbooks) is changes to the mean/accuracy of beliefs, but that changes in the uncertainty of beliefs also play a role for the larger investments that proxy more for the level of investment.

\section{Conclusion}

This paper highlights an important source of misinformation that affects decisions: parents' inaccurate beliefs about their children's academic performance. I show that (perceived) academic performance is an important input into parents' investment decisions, but that despite the ready availability of academic performance information, many parents' beliefs about their children's academic performance are quite wrong - with important consequences for the allocation of educational investments. Providing academic performance information to parents causes them to change both the level and type of investments they choose for their children. The impacts are seen across a broad range of investments, from those with very clean predictions about how parents should invest to maximize returns (e.g., remedial textbooks that are more useful for low-performing students), to more consequential investments that proxy for overall educational attainment.

It is perhaps surprising that baseline information is poor if the returns to knowledge are high and the information is, in principle, readily available. But, parents may over-estimate their own knowledge, or the (perceived) costs of acquiring information may be high, especially for uneducated or illiterate parents. Indeed, interviews with parents suggest that

\footnotetext{
${ }^{31}$ If salience effects vary and are correlated with performance, this could affect the slope. But, salience would likely be a household-level effect, or correlated with child-level controls. Online Appendix Tables G.12 and G.13, which show robustness to household fixed effects and to controlling for child-level controls interacted with treatment, thus assuage the concern. For dropouts, we lose statistical power quickly, but the coefficient for enrollment stays stable and the p-value remains $\leq 0.15$.
} 
uneducated parents are intimidated to talk with their children's teachers. These barriers to accessing information may be more pervasive in poorer countries and among poorer households. Consistent with this, I find that less-educated parents in my setting have less accurate beliefs. This same pattern is also evident in beliefs data from other contexts, including the U.S., ${ }^{32}$ and suggests a potential link between poor access to information and poverty.

This paper focused on identifying the causal chain between parents' beliefs and their investments. One area for future research would be to extend the causal chain further to better understand the link between investments and welfare, for example by measuring the objective returns to different educational investments and comparing them with parents' perceptions. A second direction for future work would be to design and test a scalable information-dissemination strategy.

${ }^{32}$ U.S. data were provided by Alexander and Entwisle (2006) and analyzed by the author. 


\section{References}

Aizer, A. and F. Cunha (2012). The production of child human capital: Endowments, investments and fertility. Unpublished paper, Brown University.

Alexander, K. and D. Entwisle (2006). Baltimore Beginning School Study, 1982-2002. The Harvard-MIT Data Centers. Henry A. Murray Research Archive. Log\# 01293.

Andrabi, T., J. Das, and A. I. Khwaja (2016). Report cards: The impact of providing school and child test scores on educational markets. Unpublished working paper.

Arcidiacono, P. et al. (2012). Modeling college major choices using elicited measures of expectations and counterfactuals. Journal of Econometrics 166(1), 3-16.

Baird, S. and B. Özler (2012). Examining the reliability of self-reported data on school participation. Journal of Development Economics 98(1), 89-93.

Banerjee, A. V., R. Banerji, E. Duflo, R. Glennerster, and S. Khemani (2010). Pitfalls of participatory programs: Evidence from a randomized evaluation in education in India. American Economic Journal: Economic Policy, 1-30.

Bergman, P. (2016). Parent-child information frictions and human capital investment: Evidence from a field experiment. Unpublished working paper.

Beshears, J., J. J. Choi, D. Laibson, B. C. Madrian, and K. L. Milkman (2015). The effect of providing peer information on retirement savings decisions. The Journal of finance $70(3)$, $1161-1201$.

Bettinger, E. P., B. T. Long, P. Oreopoulos, and L. Sanbonmatsu (2012). The role of application assistance and information in college decisions: Results from the H\&R Block FAFSA experiment. The Quarterly Journal of Economics 127(3), 1205-1242.

Bhargava, S. and D. Manoli (2015). Psychological frictions and the incomplete take-up of social benefits: Evidence from an irs field experiment. American Economic Review 105(11), 34893529.

Bobba, M. and V. Frisancho (2016). Learning about oneself: The effects of performance feedback on school choice. Technical report, TSE Working Paper.

Borghans, L., B. H. Golsteyn, J. Heckman, and J. E. Humphries (2011). Identification problems in personality psychology. Personality and individual differences 51(3), 315-320.

Borghans, L., B. H. Golsteyn, J. J. Heckman, and J. E. Humphries (2016). What grades and achievement tests measure. Proceedings of the National Academy of Sciences 113(47), 1335413359.

Bourguignon, F., F. H. Ferreira, and P. G. Leite (2003). Conditional cash transfers, schooling, and child labor: micro-simulating Brazil's Bolsa Escola program. The World Bank Economic Review $17(2)$, 229-254.

Chetty, R. and E. Saez (2009, April). Teaching the tax code: Earnings responses to an experiment 
with eitc recipients. Working Paper 14836, National Bureau of Economic Research.

Chevalier, A., S. Gibbons, A. Thorpe, M. Snell, and S. Hoskins (2009). Students' academic self-perception. Economics of Education Review 28(6), 716-727.

Dinkelman, T. and C. Martínez A (2014). Investing in schooling in Chile: The role of information about financial aid for higher education. Review of Economics and Statistics 96(2), 244-257.

Dizon-Ross, R. (2018). Identifying the (perceived) education production function: Evidence from information shocks. Working paper.

Duflo, E., P. Dupas, and M. Kremer (2011). Peer effects, teacher incentives, and the impact of tracking: Evidence from a randomized evaluation in Kenya. American Economic Review 101(5), 1739-74.

Duflo, E. and E. Saez (2000). Participation and investment decisions in a retirement plan: The influence of colleaugues' choices. Journal of Public Economics.

Dupas, P. (2011). Do teenagers respond to HIV risk information? Evidence from a field experiment in Kenya. American Economic Journal: Applied Economics, 1-34.

Eil, D. and J. M. Rao (2011). The good news-bad news effect: asymmetric processing of objective information about yourself. American Economic Journal: Microeconomics 3(2), 114-38.

Fitzsimons, E., B. Malde, A. Mesnard, and M. Vera-Hernandez (2016). Nutrition, information and household behavior: Experimental evidence from malawi. Journal of Development Economics 122, 113-126.

Hoxby, C. and S. Turner (2013). Expanding college opportunities for high-achieving, low income students. Stanford Institute for Economic Policy Research Discussion Paper.

Jamison, J. C., D. Karlan, and P. Raffler (2013). Mixed method evaluation of a passive mhealth sexual information texting service in uganda. Technical report, National Bureau of Economic Research.

Jensen, R. (2010). The (perceived) returns to education and the demand for schooling. The Quarterly Journal of Economics 125(2), 515-548.

Kling, J., S. Mullainathan, E. Shafir, L. Vermeulen, and M. Wrobel (2011, September). Comparison friction: Experimental evidence from medicare drug plans. Working Paper 17410, National Bureau of Economic Research.

Liebman, J. B. and E. F. Luttmer (2015). Would people behave differently if they better understood social security? evidence from a field experiment. American Economic Journal: Economic Policy 7(1), 275-299.

Mobius, M. and T. Rosenblat (2014). Social learning in economics. Annu. Rev. Econ. 6(1), $827-847$.

Nguyen, T. (2008). Information, role models and perceived returns to education: Experimental evidence from Madagascar. Unpublished manuscript. 
Paviot, L., N. Heinsohn, and J. Korkman (2008). Extra tuition in southern and eastern Africa: Coverage, growth, and linkages with pupil achievement. International Journal of Educational Development 28(2), 149-160.

Pitt, M. M., M. R. Rosenzweig, and M. N. Hassan (1990). Productivity, health, and inequality in the intrahousehold distribution of food in low-income countries. The American Economic Review, 1139-1156.

Rogers, T. and A. Feller (2016). Intervening through influential third parties: Reducing student absences at scale via parents.

Sternberg, R. J., C. Nokes, P. W. Geissler, R. Prince, F. Okatcha, D. A. Bundy, and E. L. Grigorenko (2001). The relationship between academic and practical intelligence: A case study in kenya. Intelligence 29(5), 401-418.

Stinebrickner, R. and T. Stinebrickner (2014). A major in science? Initial beliefs and final outcomes for college major and dropout. The Review of Economic Studies 81(1), 426-472.

Stinebrickner, T. and R. Stinebrickner (2012). Learning about academic ability and the college dropout decision. Journal of Labor Economics 30(4), 707-748.

Wiswall, M. and B. Zafar (2015). Determinants of college major choice: Identification using an information experiment. The Review of Economic Studies 82(2), 791-824.

World Bank (1998). World Development Report 1998/1999: Knowledge for Development. Oxford University Press.

World Bank (2008). World development report 2008: Agriculture for development. Technical report, World Bank.

World Bank (2010). The education system in Malawi. Policy report, World Bank. 
Figure 1: Empirical approach: Inaccurate beliefs about performance can cause the slope of investments as a function of academic performance to differ from the slope as a function of beliefs

(a) Beliefs may be inaccurate, for example attenuated on true performance (slope $<1$ ).

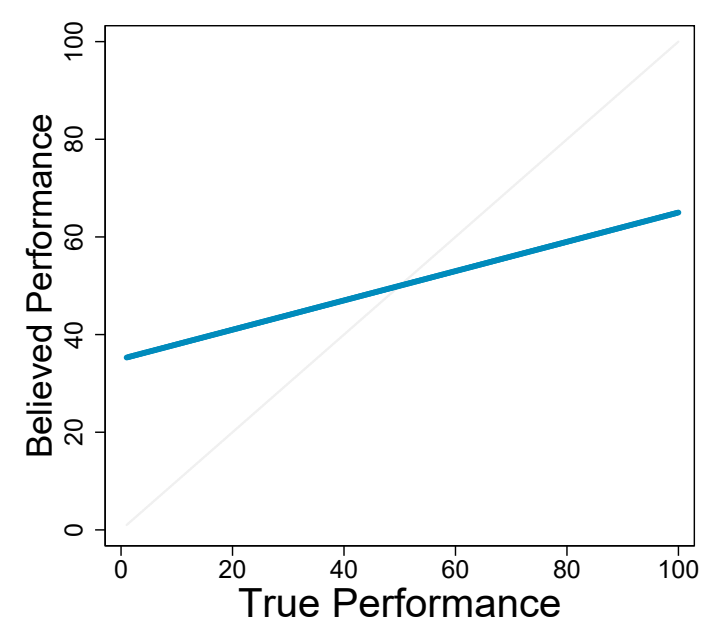

(b) Parents choose their investments based on their (inaccurate) beliefs.

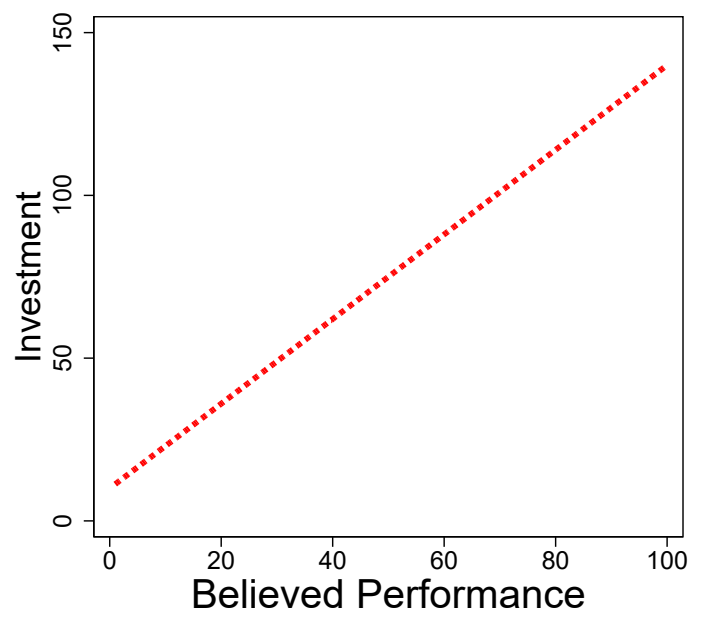

(c) The slope of investments on true performance may thus be attenuated relative to the slope on beliefs.

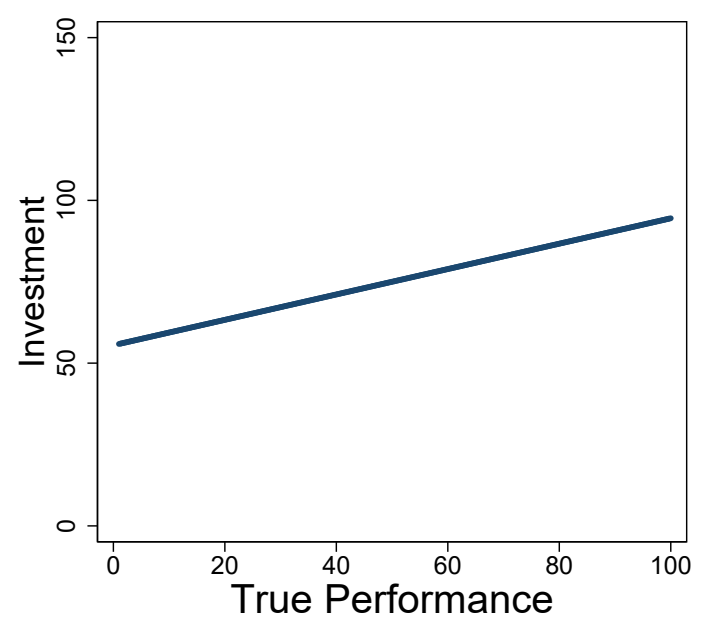

Notes: Graphs are illustrative, showing one way to test whether parents' inaccurate beliefs affect their investments. A common type of belief inaccuracy is that beliefs will be "attenuated" on true performance, i.e., have a slope less than 1 on true performance (panel (a)). Parents base their investments on their potentially inaccurate beliefs, and so plotting investments on beliefs shows us parents' "preferred" slope, i.e., the slope they would opt to choose if they knew their children's true performance (panel (b)). However, because beliefs are inaccurate - and in particular, attenuated - the slope of investments as a function of children's true academic performance is flatter than the slope on beliefs (panel (c)). The interpretation of the difference in slopes is that investments are not as well tailored to academic performance as parents would like. 
Figure 2: Overview of data collection

Day 1

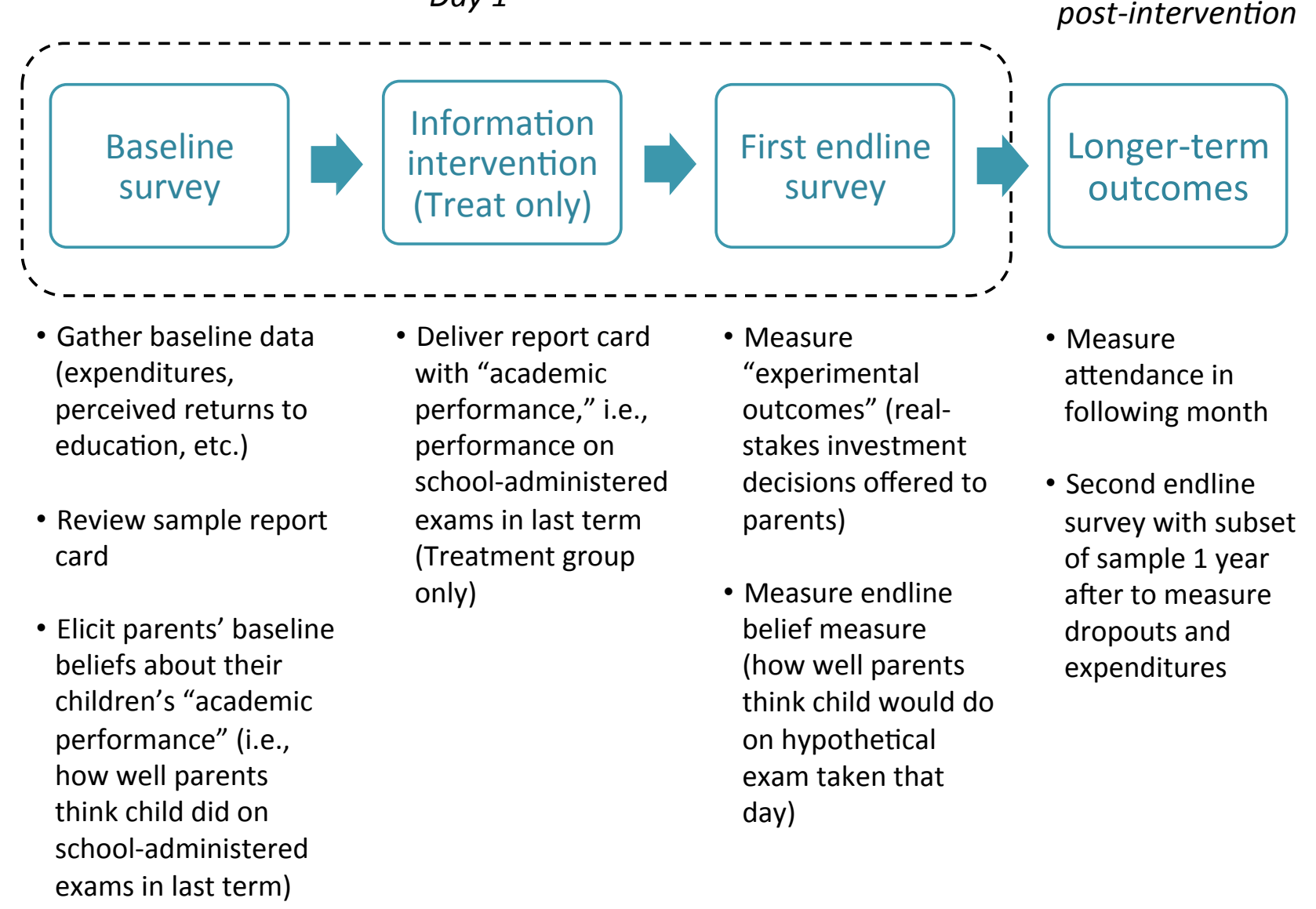

0-12 months
post-intervention 
Figure 3: Beliefs results

(a) Gap between true test scores last term and baseline beliefs about scores last term

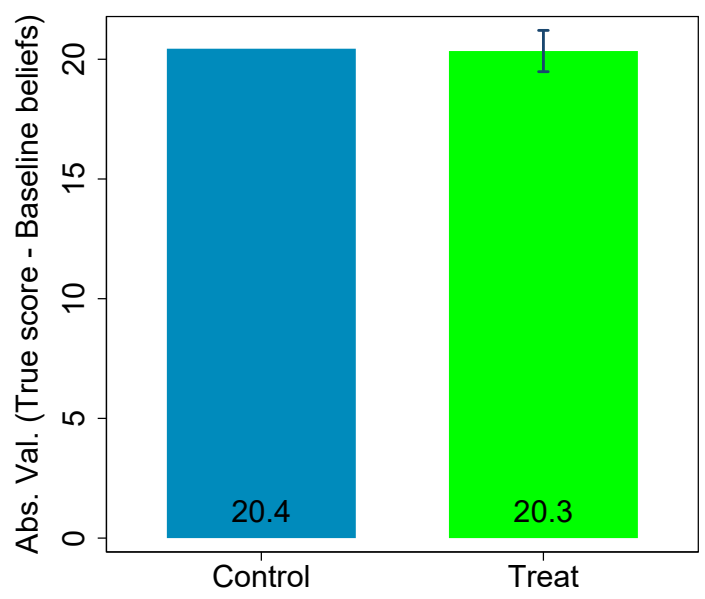

(b) Attenuation of baseline beliefs

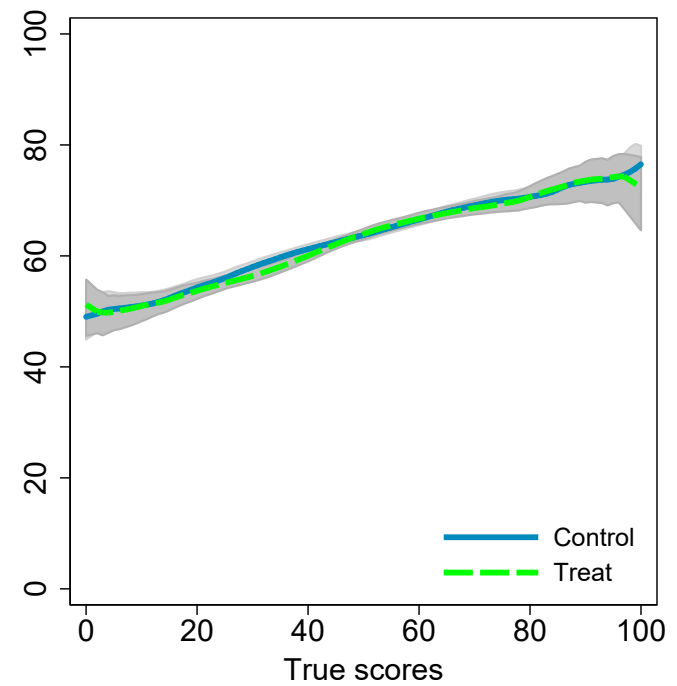

(c) Gap between true test scores

last term and endline beliefs about

likely score on hypothetical test

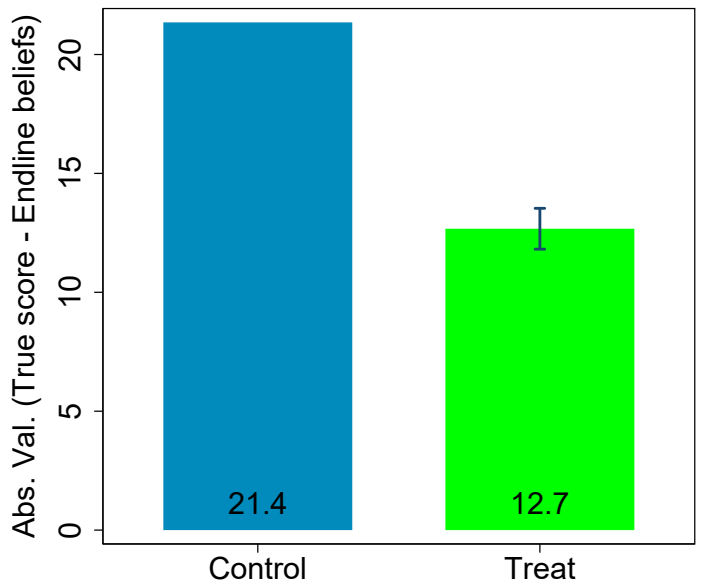

(d) Attenuation of endline beliefs

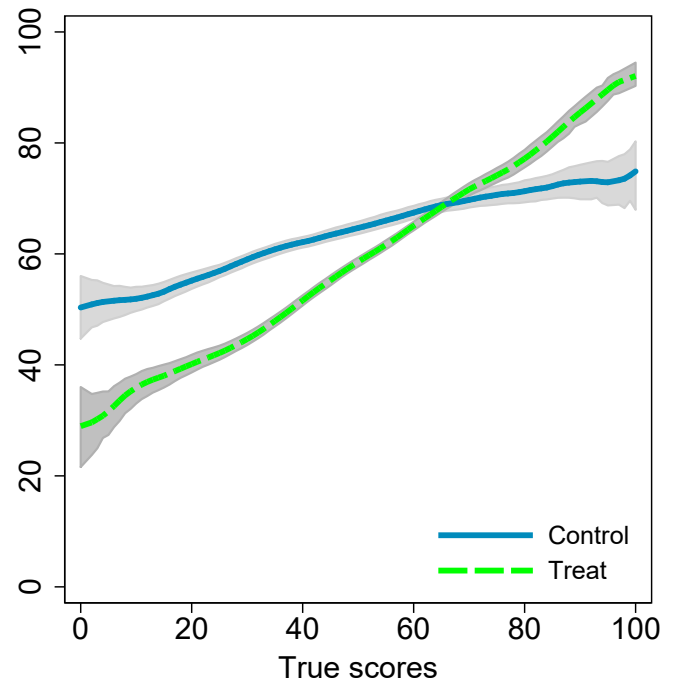

Notes: Data sources are survey data and administrative baseline test score data. Scores are absolute percentages, expressed on a scale from 0 to 100. All scores and beliefs are about overall (as opposed to subject-specific) performance. Panel (a) displays the average absolute value of the gap between children's true test scores last term and parents' beliefs (measured at baseline) about these test scores; it shows that inaccacuracies are large, and balanced across the control and treatment groups. Panel (b) shows attenuation in baseline beliefs by plotting locally linear regression lines with beliefs about last-term test scores as the dependent variable and true test scores as the $\mathrm{x}$-axis; it shows that baseline beliefs are attenuated (i.e., that the slope is less than 1 and so they do not move 1-to-1 with true scores), and that this is balanced across the treatment and control groups. Panel (c) displays the average absolute value of the gap between children's last-term true test scores and parents' beliefs (measured at endline) about their children's performance on a hypothetical test taken that same day; it shows that information moves parents beliefs towards the signal. Panel (d) shows attenuation in endline beliefs by plotting locally linear regression lines with beliefs (measured during the first endline survey) about performance on a hypothetical test as the dependent variable and last-term true test scores as the $\mathrm{x}$-axis; it shows that information decreases the attenuation. 
Figure 4: In the control group, the slope of investments on true academic performance is attenuated relative to the slope on believed performance

\section{(Control group only)}

\section{(a) Difficulty level chosen for free workbooks}
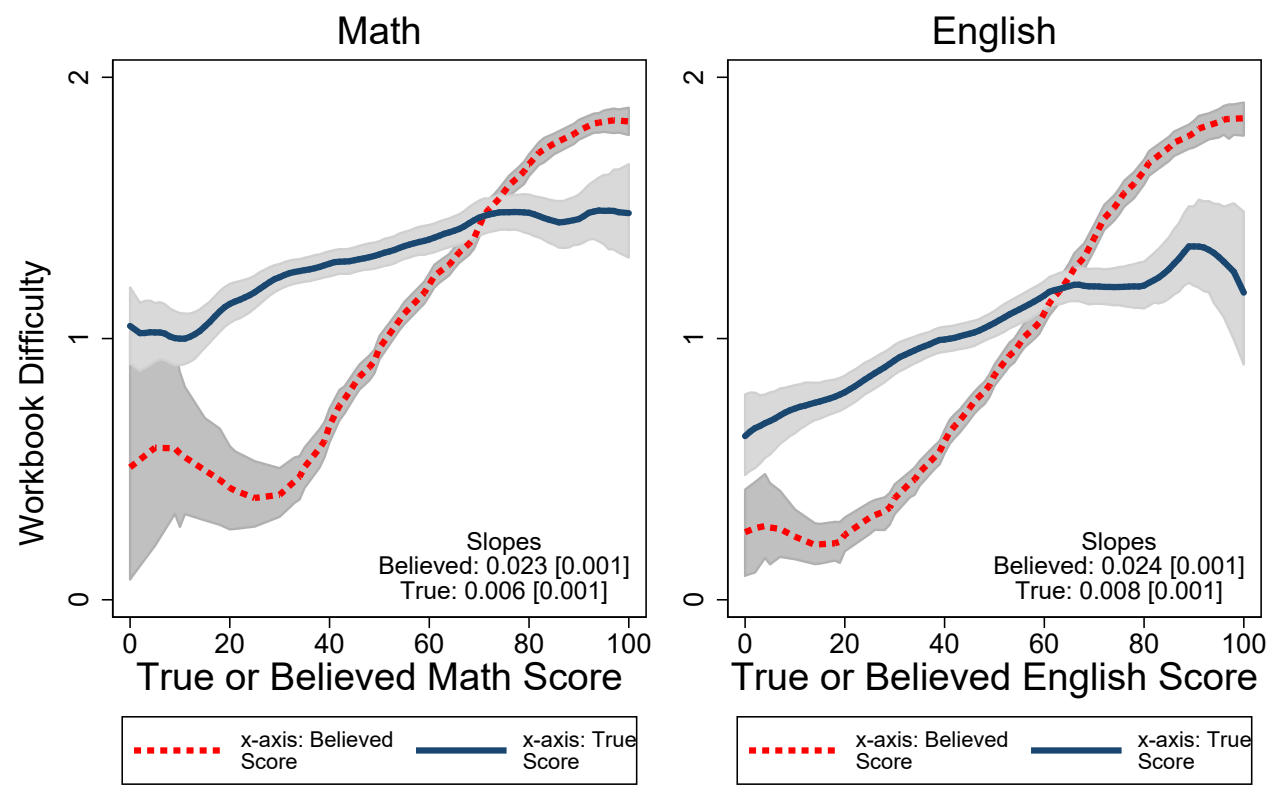

(b) WTP for remedial textbooks

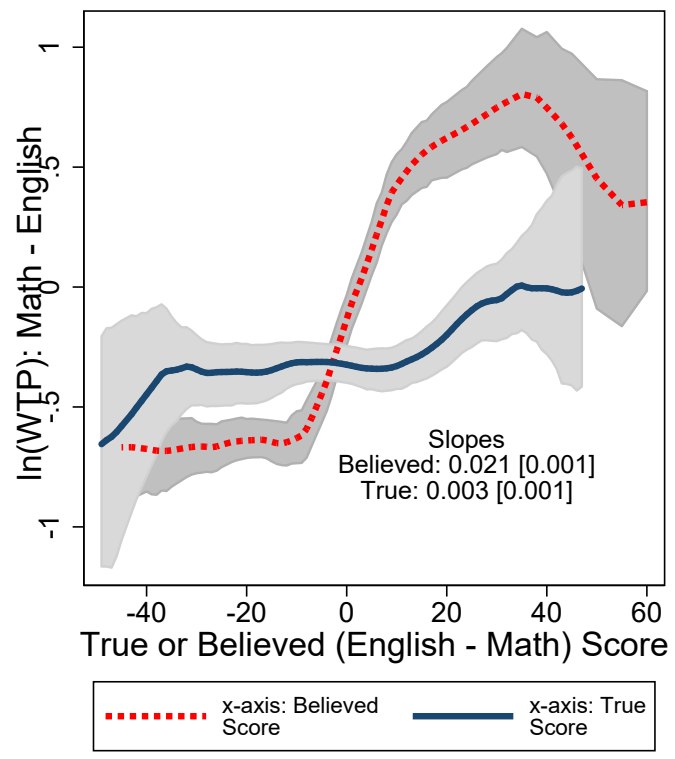

(c) Secondary school lottery

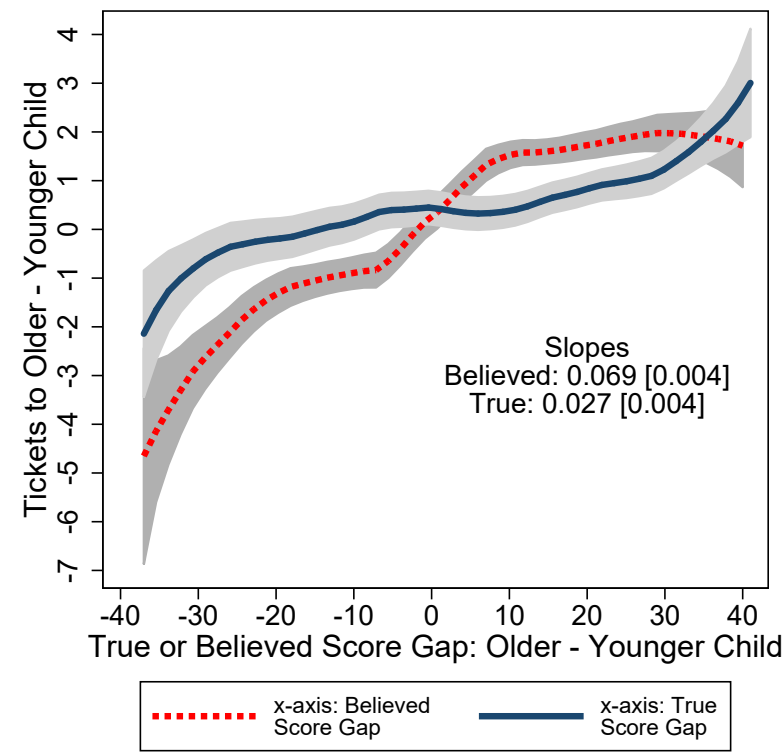

Notes: Control group data only. Data sources are survey data and administrative baseline test score data. Lines are locally linear regression lines with investments as the dependent variable and either true (solid line) or believed (dashed line) baseline academic performance as the x-axis. For the workbook graphs (panel (a)), the dependent variable is the parent's choice of difficulty for a free workbook, where 0 corresponds to the beginner workbook, 1 corresponds to the average, and 2 to the advanced. For textbook WTP (panel (b)), the dependent variable is the difference in the parent's log WTP for a remedial math textbook relative to a remedial English textbook. Because the textbooks are remedial, the prediction is that this should increase in the child's English relative to math performance. For the secondary school lottery (panel (c)), the dependent variable is the number of secondary school lottery tickets given to the older relative to younger child in the household, and the believed score gap is the gap in parents' beliefs about their children's overall test scores. The grey areas are $95 \%$ confidence intervals. 
Figure 5: The information treatment increases the slope of investments on true academic performance

(a) Difficulty level chosen for free workbooks
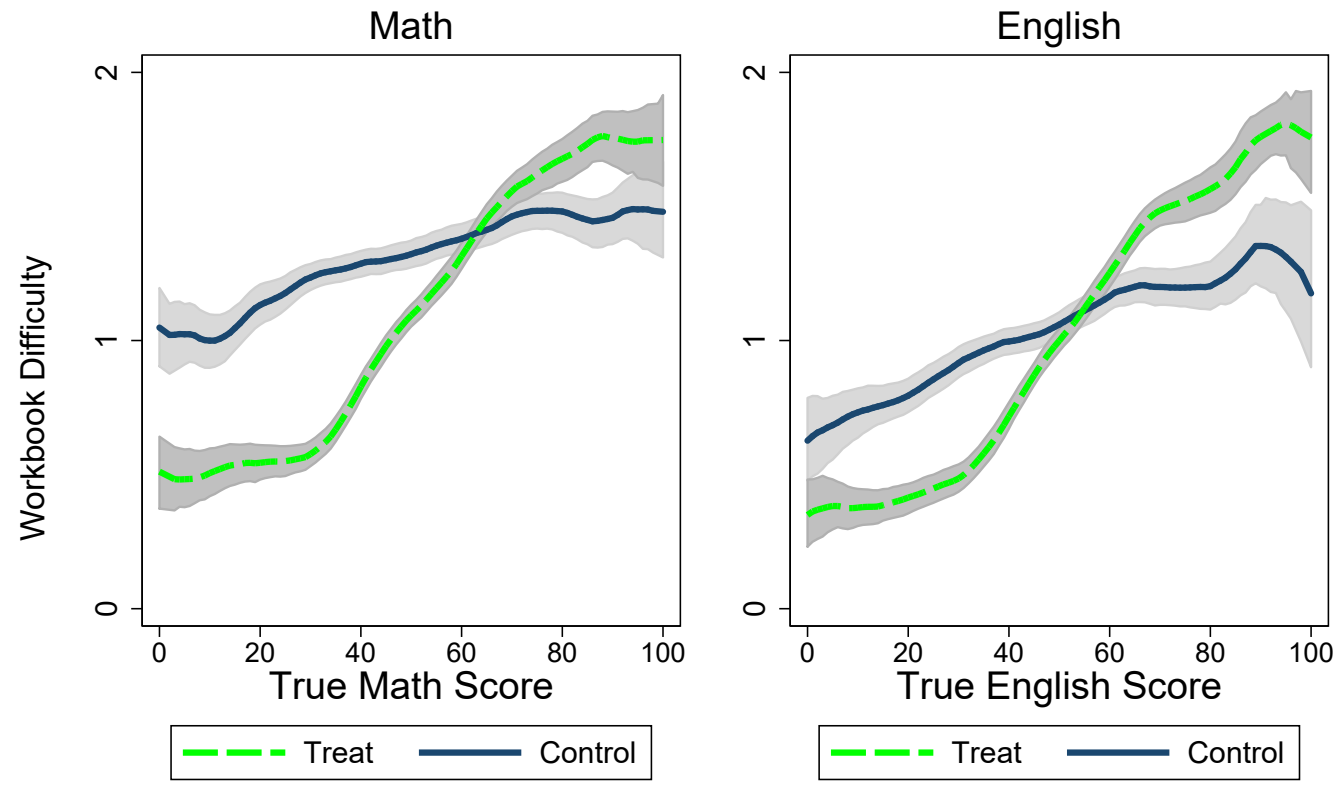

(b) WTP for remedial textbooks

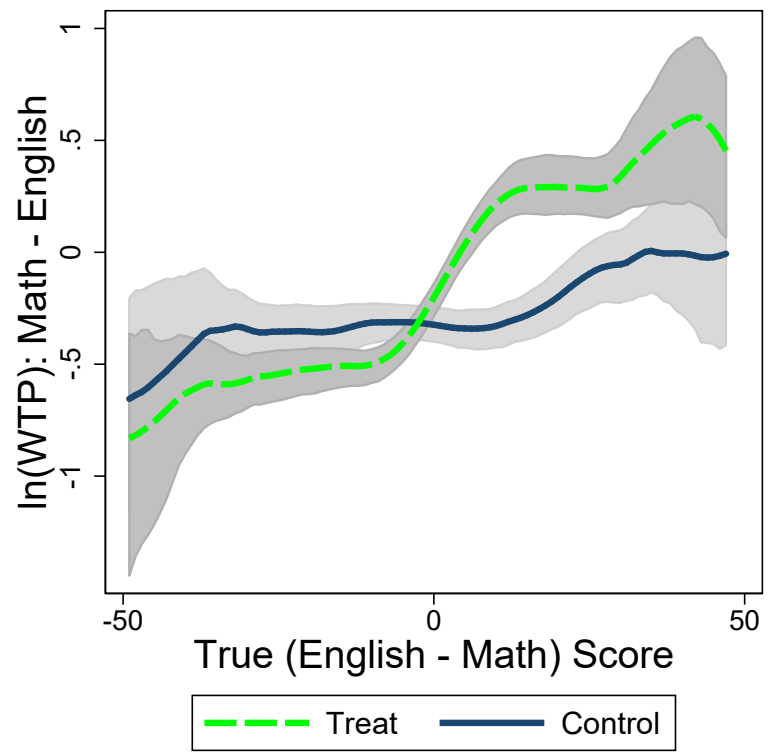

(c) Secondary school lottery

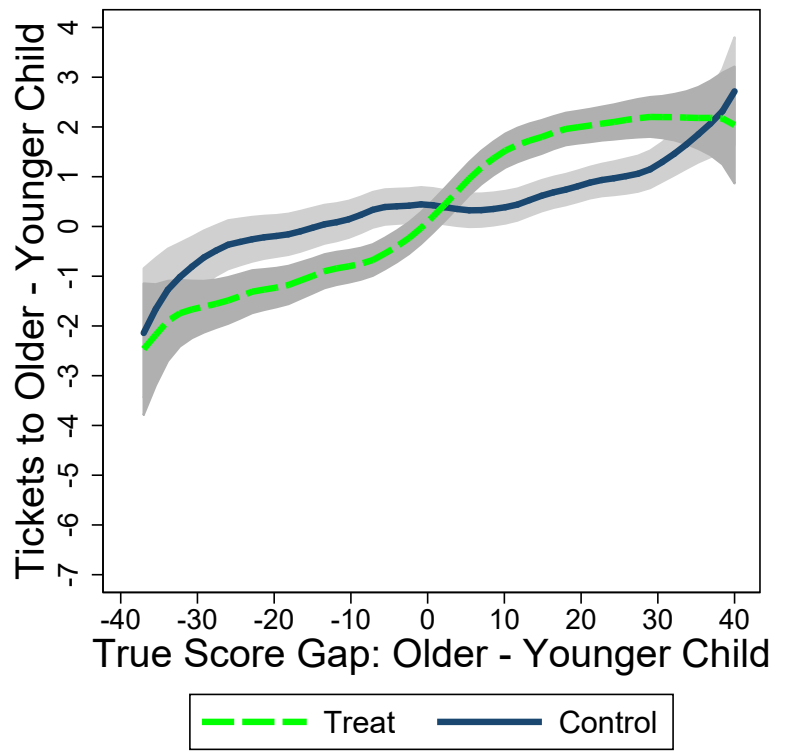

Notes: Data sources are survey data and administrative baseline test score data. Lines are locally linear regression lines with investments as the dependent variable and either true (solid line) or believed (dashed line) baseline academic performance as the x-axis. For the workbook graphs (panel (a)), the dependent variable is the parent's choice of difficulty for a free workbook, where 0 corresponds to the beginner workbook, 1 corresponds to the average, and 2 to the advanced. For textbook WTP (panel (b)), the dependent variable is the difference in the parent's log WTP for a remedial math textbook relative to a remedial English textbook. Because the textbooks are remedial, the prediction is that this should increase in the child's English relative to math performance. For the secondary school lottery (panel (c)), the dependent variable is the number of secondary school lottery tickets given to the older relative to younger child in the household, and the believed score gap is the gap in parents' beliefs about their children's overall test scores. The grey areas are $95 \%$ confidence intervals. 
Table 1: Baseline summary statistics

\begin{tabular}{|c|c|c|c|c|c|c|c|}
\hline \multirow[b]{3}{*}{ A. Respondent Background } & \multicolumn{2}{|c|}{ Full sample } & \multirow{2}{*}{$\begin{array}{l}\text { Control } \\
\text { Mean }\end{array}$} & \multirow{2}{*}{$\begin{array}{l}\text { Treat } \\
\text { Mean }\end{array}$} & \multicolumn{3}{|c|}{ Treat - Control } \\
\hline & Mean & $\mathrm{SD}$ & & & Mean & $\begin{array}{l}\text { Std. } \\
\text { error }\end{array}$ & $\begin{array}{l}\mathrm{p}-\mathrm{val} \\
\mathrm{T}=\mathrm{C}\end{array}$ \\
\hline & & & & & & & \\
\hline $\begin{array}{l}\text { A. Respondent Background } \\
\text { Female }\end{array}$ & 0.77 & 0.42 & 0.77 & 0.76 & -0.01 & 0.02 & 0.37 \\
\hline Primary education decision maker & 0.92 & 0.27 & 0.91 & 0.92 & 0.01 & 0.01 & 0.31 \\
\hline Age & 40.8 & 11.0 & 40.6 & 41.0 & 0.32 & 0.44 & 0.47 \\
\hline Education (years) & 4.44 & 3.57 & 4.42 & 4.45 & 0.04 & 0.13 & 0.78 \\
\hline Respondent has secondary education + & 0.11 & 0.31 & 0.11 & 0.11 & 0.01 & 0.01 & 0.62 \\
\hline Parent can read or write Chichewa & 0.67 & 0.47 & 0.67 & 0.68 & 0.01 & 0.02 & 0.67 \\
\hline Respondent is farmer & 0.46 & 0.5 & 0.47 & 0.46 & -0.01 & 0.02 & 0.7 \\
\hline Respondent's weekly income & 2,126 & 4,744 & 2,051 & 2,203 & 197 & 194 & 0.31 \\
\hline \multicolumn{8}{|l|}{ B. Household Background } \\
\hline$\overline{\text { Family size }(\text { Number of children }}{ }^{\mathrm{a}}$ ) & 5.13 & 1.74 & 5.16 & 5.1 & -0.05 & 0.07 & 0.47 \\
\hline One-parent household & 0.19 & 0.39 & 0.19 & 0.2 & 0.01 & 0.02 & 0.47 \\
\hline Parents' average education (years) & 4.66 & 3.25 & 4.68 & 4.64 & -0.04 & 0.12 & 0.74 \\
\hline Any parent has secondary education + & \multicolumn{6}{|c|}{ C. Student Information } & 0.24 \\
\hline Child's grade level & 3.72 & 1.37 & 3.72 & 3.72 & 0 & 0.04 & 0.94 \\
\hline Child's age & 11.6 & 2.68 & 11.7 & 11.6 & -0.1 & 0.08 & 0.21 \\
\hline Child is female & 0.51 & 0.5 & 0.52 & 0.5 & -0.02 & 0.01 & 0.25 \\
\hline Baseline attendance & 0.91 & 0.13 & 0.92 & 0.91 & 0 & 0 & 0.72 \\
\hline Annual per-child education expenditures & 1,742 & 2,791 & 1,712 & 1,772 & 58.0 & 83.0 & 0.48 \\
\hline Fees paid to schools & 381 & 1,128 & 384 & 378 & -6.84 & 23.9 & 0.78 \\
\hline Uniform expense & 576 & 1,019 & 548 & 603 & 49.9 & 36.1 & 0.17 \\
\hline School supplies, books, tutoring, etc. ${ }^{\mathrm{b}}$ & 785 & 1,819 & 780 & 790 & 14.3 & 62.3 & 0.82 \\
\hline Any supplementary expenditures on child & 0.9 & 0.3 & 0.9 & 0.89 & -0.01 & 0.01 & 0.49 \\
\hline \multicolumn{8}{|c|}{ D. Academic Performance (Average Achievement Scores) } \\
\hline Overall score & 46.8 & 17.5 & 47.1 & 46.4 & -0.74 & 0.46 & 0.11 \\
\hline Math score & 44.9 & 20.2 & 45.4 & 44.4 & -1.08 & 0.54 & 0.04 \\
\hline English score & 44.2 & 20.1 & 44.5 & 43.9 & -0.56 & 0.53 & 0.29 \\
\hline Chichewa score & 51.3 & 22.6 & 51.5 & 51.0 & -0.57 & 0.59 & 0.34 \\
\hline (Math - English) Score & 0.71 & 19.5 & 0.93 & 0.5 & -0.53 & 0.51 & 0.3 \\
\hline \multicolumn{8}{|c|}{ E. Respondent's Beliefs about Child's Academic Performance } \\
\hline Believed Overall Score & 62.4 & 16.5 & 62.7 & 62.0 & -0.78 & 0.48 & 0.11 \\
\hline Believed Math Score & 64.7 & 19.0 & 65.2 & 64.3 & -0.94 & 0.55 & 0.09 \\
\hline Believed English Score & 55.3 & 20.9 & 55.6 & 54.9 & -0.71 & 0.62 & 0.25 \\
\hline Believed Chichewa Score & 66.8 & 19.4 & 66.8 & 66.7 & -0.1 & 0.6 & 0.87 \\
\hline Beliefs about (Math - English) Score & 9.48 & 21.5 & 9.59 & 9.37 & -0.23 & 0.63 & 0.71 \\
\hline SD of Individual Beliefs about Score & 7.69 & 10.1 & 8.08 & 7.28 & -0.8 & 0.38 & 0.03 \\
\hline \multicolumn{8}{|c|}{ F. Gaps Between Believed and True Academic Performance } \\
\hline Abs Val [Believed - True Overall Score] & 20.4 & 14.5 & 20.4 & 20.3 & -0.12 & 0.43 & 0.77 \\
\hline Abs Val [Believed - True Math Score] & 25.8 & 18.0 & 25.8 & 25.7 & -0.1 & 0.52 & 0.85 \\
\hline Abs Val [Believed - True English Score] & 21.4 & 16.4 & 21.6 & 21.1 & -0.57 & 0.48 & 0.23 \\
\hline Abs Val [Believed - True Chichewa Score] & 23.8 & 17.5 & 23.7 & 23.9 & 0.18 & 0.51 & 0.73 \\
\hline Abs Val [Believed - True (Math-English) Score] & 22.1 & 17.4 & 22.3 & 21.9 & -0.44 & 0.51 & 0.39 \\
\hline Abs Val [Believed - True Overall Score (Child1-2)] & 18.7 & 15.1 & 18.9 & 18.5 & -0.35 & 0.59 & 0.55 \\
\hline Believed - True Overall Score & 15.6 & 19.5 & 15.6 & 15.6 & -0.07 & 0.58 & 0.9 \\
\hline Believed score higher than true score & 0.79 & 0.41 & 0.79 & 0.79 & 0.01 & 0.01 & 0.65 \\
\hline $\begin{array}{l}\text { Wrong about who (child } 1 \text { or } 2 \text { ) is higher-scoring } \\
\text { G. Beliefs about Complementarity }\end{array}$ & 0.31 & 0.46 & 0.32 & 0.31 & -0.01 & 0.02 & 0.63 \\
\hline $\begin{array}{l}\text { G. Beliets about Complementarity } \\
\text { Believes educ. and achievement complementary }\end{array}$ & 0.91 & 0.29 & 0.9 & 0.91 & 0 & 0.01 & 0.68 \\
\hline Sample Sizes & & & & & & & \\
\hline 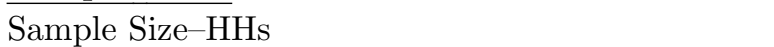 & 2,634 & & 1,3 & 1,307 & & & \\
\hline Sample Size-Kids & 5,268 & & 2,654 & 2,614 & & & \\
\hline
\end{tabular}

Notes: Data source is baseline survey. Standard errors for the test of equality across treatment and control clustered at the household level.

a. Counted as a child if either of the primary caregivers for the sampled children is a parent of the child.

b. Includes exercise books and pencils, textbooks and supplementary reading books, backpacks, and tutoring expenses. c. Respondent said that they thought the earnings of a higher-performing child would increase "more" or "much more" than the earnings of a lower-performing child from getting a secondary education. 
Table 2: Experimental outcomes: Information treatment effects on the slope of investments on academic performance

\begin{tabular}{|c|c|c|c|c|c|}
\hline Dependent variable: & $\begin{array}{l}\text { Endline beliefs } \\
\text { (1) }\end{array}$ & $\begin{array}{c}\text { Math workbook } \\
\text { difficulty level } \\
\text { (2) }\end{array}$ & $\begin{array}{c}\text { English } \\
\text { workbook } \\
\text { difficulty level } \\
(3)\end{array}$ & $\begin{array}{c}\ln \text { (math textbook } \\
\text { WTP })- \\
\ln (\text { English } \\
\text { textbook WTP }) \\
(4)\end{array}$ & $\begin{array}{c}\text { Secondary school } \\
\text { lottery tickets } \\
\text { (5) }\end{array}$ \\
\hline Treat $\times$ Score & $\begin{array}{c}0.41 \\
{[0.025]}\end{array}$ & $\begin{array}{c}1.34 \\
{[0.093]}\end{array}$ & $\begin{array}{c}1.25 \\
{[0.096]}\end{array}$ & $\begin{array}{c}0.013 \\
{[0.0022]}\end{array}$ & $\begin{array}{c}0.036 \\
{[0.0052]}\end{array}$ \\
\hline Score & $\begin{array}{c}0.31 \\
{[0.017]}\end{array}$ & $\begin{array}{c}0.65 \\
{[0.065]}\end{array}$ & $\begin{array}{c}0.76 \\
{[0.073]}\end{array}$ & $\begin{array}{c}0.0025 \\
{[0.0016]}\end{array}$ & $\begin{array}{c}0.015 \\
{[0.0051]}\end{array}$ \\
\hline Treat & $\begin{array}{l}-26.2 \\
{[1.33]}\end{array}$ & $\begin{array}{l}-91.0 \\
{[4.91]}\end{array}$ & $\begin{array}{l}-68.3 \\
{[4.84]}\end{array}$ & $\begin{array}{c}0.14 \\
{[0.041]}\end{array}$ & \\
\hline $\begin{array}{l}\text { Observations } \\
\text { R-squared }\end{array}$ & $\begin{array}{l}5,244 \\
0.339\end{array}$ & $\begin{array}{l}5,239 \\
0.217\end{array}$ & $\begin{array}{l}5,239 \\
0.205\end{array}$ & $\begin{array}{l}5,219 \\
0.035\end{array}$ & $\begin{array}{l}5,258 \\
0.154\end{array}$ \\
\hline $\begin{array}{l}\text { Score Used } \\
\text { Household FE }\end{array}$ & $\begin{array}{l}\text { Overall } \\
\text { No }\end{array}$ & $\begin{array}{l}\text { Math } \\
\text { No }\end{array}$ & $\underset{\text { No }}{\text { English }}$ & $\begin{array}{c}\text { English }- \text { Math } \\
\text { No }\end{array}$ & $\begin{array}{l}\text { Overall } \\
\text { Yes }\end{array}$ \\
\hline
\end{tabular}

Notes: Data sources are baseline survey, baseline test score data, both endline surveys, and endline administrative data. Each observation is a child. Standard errors are clustered at the household level. Workbook difficulty choices are coded as 0 for beginner, 100 for average, and 200 for advanced. The dependent variable in Column (1) corresponds to the parent's endline beliefs about the child's overall score on a hypothetical test taken the same day as the endline survey.

The regressions test for whether information changes the slope of investments on children's academic performance (where academic performance is measured as children's average scores on school-administered achievement exams). One way to interpret the results is to compare the baseline slope in the control group (coefficient on Score) with the increase in the slope in the treatment group (coefficient on Treat $\times$ Score) to see how much the slope has increased as a result of information. Take for example column (2). The ratio of the coefficient on Treat $\times$ Score (1.34) to the coefficient on Score (0.65) shows us that the slope has increased by roughly $200 \%(1.34 / 0.65)$, so that the treatment slope is roughly 3 times as large as the control slope. The rough interpretation of the slope in the control group for that column is that, if the child's math score increases by one point, the chance that her parent chooses the next higher difficulty level of the free book increases by $.65 \%$. Regressions control for school FE, average parental years of education, the between-child score gap, child gender, grade FE, and parent gender; column (5) also has a household FE. 
Table 3: Treatment effects on the slope for longer-term outcomes: Full-sample estimates

\begin{tabular}{|c|c|c|c|}
\hline \multirow{2}{*}{ Dependent variable: } & Enrollment & $\begin{array}{l}\ln \text { (Total educ. } \\
\text { expenditures) }\end{array}$ & $\begin{array}{c}\text { Attendance } \\
\text { rate }\end{array}$ \\
\hline & $(1)$ & $(2)$ & $(3)$ \\
\hline \multicolumn{4}{|c|}{ PANel A. Continuous versions } \\
\hline Treat $\times$ Score & $\begin{array}{c}0.10 \\
{[0.038]}\end{array}$ & $\begin{array}{l}-0.0019 \\
{[0.0022]}\end{array}$ & $\begin{array}{c}0.021 \\
{[0.048]}\end{array}$ \\
\hline Treat & $\begin{array}{l}-5.28 \\
{[2.10]}\end{array}$ & $\begin{array}{l}0.086 \\
{[0.11]}\end{array}$ & $\begin{array}{l}-1.36 \\
{[2.60]}\end{array}$ \\
\hline \multicolumn{4}{|l|}{ PANEL B. BINARY VERSIONS } \\
\hline Treat $\times$ Above-median score & $\begin{array}{l}3.71 \\
{[1.45]}\end{array}$ & $\begin{array}{l}-0.030 \\
{[0.074]}\end{array}$ & $\begin{array}{l}-0.17 \\
{[1.53]}\end{array}$ \\
\hline Treat & $\begin{array}{l}-2.20 \\
{[1.15]}\end{array}$ & $\begin{array}{c}0.014 \\
{[0.061]}\end{array}$ & $\begin{array}{l}-0.15 \\
{[1.24]}\end{array}$ \\
\hline Observations & 1,786 & 1,709 & 1,827 \\
\hline Control group mean & 97.9 & 7.4 & 91.1 \\
\hline Score Used & Overall & Overall & Overall \\
\hline
\end{tabular}

Notes: Data sources are baseline survey, baseline test score data, endline survey and endline data collected from schools. Each observation is a child. Standard errors clustered at the household level. All regressions also control for grade FE, school FE, the between-child score gap, household-average years of parental education (continuous in Panel A, whether above median in Panel B), child gender, parent gender, and the baseline value of the dependent variable, if available (not available for enrollment). Enrollment is defined as being enrolled in school 1 year after the intervention. Both enrollment and attendance are scaled to be out of 100 (so enrollment, for example, is equal to 100 if the child is still enrolled and 0 otherwise). Above-median score means the child had an above-median baseline overall score. 
Table 4: Heterogeneity by parent education in belief inaccuracies and treatment effects

Panel A. Attenuation of Beliefs

\begin{tabular}{lcccccc}
\hline \hline & \multicolumn{7}{c}{ Parent beliefs about child's score in: } \\
\cline { 2 - 7 } Dependent variable: & Overall & Math & English & Chichewa & Math - Engl & Child $2-1$ \\
& $(1)$ & $(2)$ & $(3)$ & $(4)$ & $(5)$ & $(6)$ \\
\hline Score $\times$ Parents yrs of educ. & 0.014 & 0.018 & 0.014 & 0.0098 & 0.013 & 0.017 \\
& {$[0.0038]$} & {$[0.0038]$} & {$[0.0043]$} & {$[0.0036]$} & {$[0.0047]$} & {$[0.0049]$} \\
Score & 0.25 & 0.13 & 0.22 & 0.20 & 0.091 & 0.32 \\
& {$[0.023]$} & {$[0.023]$} & {$[0.026]$} & {$[0.021]$} & {$[0.029]$} & {$[0.028]$} \\
Parent yrs of educ. & -0.53 & -0.98 & -0.065 & -0.32 & -0.78 & 0.044 \\
& {$[0.20]$} & {$[0.20]$} & {$[0.21]$} & {$[0.23]$} & {$[0.094]$} & {$[0.12]$} \\
Observations & 5,220 & 5,222 & 5,222 & 5,222 & 5,222 & 5,218 \\
\hline \hline
\end{tabular}

Panel B. Selected Experimental Outcomes:

HETEROGENEITY IN THE TREATMENT EFFECT ON THE SLOPE, BY PARENT EDUCATION

\begin{tabular}{llll}
\hline \hline Dependent variable: & Endline beliefs & $\begin{array}{c}\text { Math workbook } \\
\text { difficulty level }\end{array}$ & $\begin{array}{c}\text { English workbook } \\
\text { difficulty level }\end{array}$
\end{tabular}

$(1)$

Treat $\times$ Score $\times$ Parent yrs of educ.

Treat $\times$ Score

Score $\times$ Parent yrs of educ.

Score

Treat $\times$ Parent yrs of educ.

Treat

Parent yrs of educ.

Observations

R-squared

P-val: Treat $\times$ Score $\times$ Yrs.Educ. $=0$

Score Used

0.53

0.21
(2)

(3)

-0.12
$[0.027]$
1.92
$[0.16]$
0.078
$[0.020]$

$-0.066$

[0.029]

[0.0071]

[0.044]

0.022

[0.0051]

0.29

1.57

[0.17]

0.032

[0.022]

[0.11]

0.61

[0.031]

6.48

[1.46]

[0.13]

1.22

[0.39]

$-121.5$

$-31.9$

[8.58]

2.29

[1.53]

$-79.1$

[8.59]

$-0.79$

$-3.86$

[1.08]

$-0.29$

[1.18]

5,208

5,203

5,203

0.220

0.207

0.000

$5.0 \mathrm{e}-06$

0.022

Overall

Math

English

Notes: Data sources are baseline survey and baseline test score data. Each observation is a child. Standard errors are clustered at the household level. "Parent yrs of educ." is the household-average years of parental education. Panel A displays regressions of parents' baseline beliefs about their children's true score on their children's true score, average parental years of education, and the interaction. The prediction is that true scores will be more highly correlated with the beliefs of more-educated parents, and that the coefficient on "Score $\times$ Parent yrs educ." will be positive. The child and parent controls include a control for child gender, grade FE, parent gender, and whether the parent is the primary education decisionmaker. Panel B shows the heterogeneity by parent education in the information treatment effect on the gradient of the investment function. The dependent variable in Column (1) corresponds to the parent's endline beliefs about the child's overall score on a hypothetical test taken the same day as the endline survey. Regressions control for school FE, the between-child score gap, child gender, grade $\mathrm{FE}$, and parent gender. 


\section{Appendix \\ (For Online Publication)}

\section{Table of Contents}

A. Appendix Tables

A.1 Belief Accuracy, Uncertainty, Overconfidence, and Children's Academic Performance . . . . . . . . . . . . . . . . . . 38

A.2 Average treatment effects . . . . . . . . . . . . . . . . . . 39

A.3 Asymmetric responses to positive vs. negative information shocks . . . . . . 40

A.4 Uncertainty tests: Effect of information on the slope of the preferred investment function . . . . . . . . . . . . . . . . . 41

B Sample information intervention report card $\quad 42$

C Appendix to Section 2 (Empirical approach) 43

D Results for secondary outcomes $\quad 45$

E Discussion of the absence of an ATE for enrollment 46

F Mechanisms: The role of uncertainty in beliefs $\quad 47$

Note: Appendices G through L (including all "Online Appendix Tables" and all references to the "Online Appendix") can be found in the "Supplementary Online Appendix" document found at the below link:

http://faculty.chicagobooth.edu/rebecca.dizon-ross/research/papers/perceptionsOnlineApp.pdf 
Appendix Table A.1: Belief Accuracy, Uncertainty, Overconfidence, and Children's Academic Performance

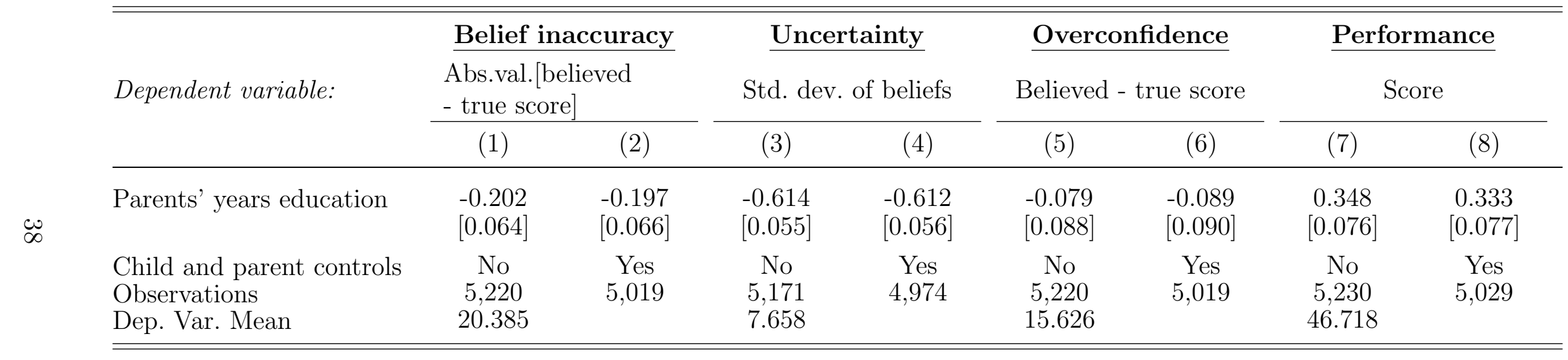

Notes: Data sources are baseline survey and baseline test score data. Each observation is a child. Standard errors are clustered at the household level. "Parents' years education" is the household-average years of parental education. Scores and beliefs are about overall performance. The child and parent controls include a control for child gender, grade FE, parent gender, and whether the parent is the primary education decisionmaker. 
Appendix Table A.2: Average treatment effects

\begin{tabular}{|c|c|c|c|c|c|c|c|}
\hline \multirow[b]{2}{*}{ Dependent variable: } & \multicolumn{4}{|c|}{ Experimental outcomes } & \multicolumn{3}{|c|}{ Non-experimental outcomes } \\
\hline & $\begin{array}{l}\text { Endline } \\
\text { beliefs }\end{array}$ & $\begin{array}{c}\text { Math } \\
\text { workbook } \\
\text { difficulty } \\
\text { level } \\
\\
(2)\end{array}$ & $\begin{array}{c}\text { English } \\
\text { workbook } \\
\text { difficulty } \\
\text { level } \\
(3)\end{array}$ & $\begin{array}{c}\ln (\text { math } \\
\text { textbook } \\
\text { WTP) - } \\
\ln (\text { English } \\
\text { textbook } \\
\text { WTP) } \\
(4)\end{array}$ & Enrollment & $\begin{array}{l}\ln (\text { Total } \\
\text { educ. } \\
\text { expendi- } \\
\text { tures) } \\
(6)\end{array}$ & $\begin{array}{l}\text { Attendance } \\
\text { rate }\end{array}$ \\
\hline \multicolumn{8}{|c|}{ Panel A. Average treatment effects } \\
\hline Treat & $\begin{array}{l}-7.47 \\
{[0.53]}\end{array}$ & $\begin{array}{l}-32.4 \\
{[2.16]}\end{array}$ & $\begin{array}{l}-13.7 \\
{[2.25]}\end{array}$ & $\begin{array}{c}0.14 \\
{[0.041]}\end{array}$ & $\begin{array}{l}-0.39 \\
{[0.71]}\end{array}$ & $\begin{array}{l}0.0024 \\
{[0.049]}\end{array}$ & $\begin{array}{l}-0.16 \\
{[0.79]}\end{array}$ \\
\hline Observations & 5,244 & 5,239 & 5,239 & 5,219 & 1,786 & 1,709 & 1,827 \\
\hline \multicolumn{8}{|c|}{ PANEL B. UnCERTAinty LEVEL EFFECTS: Beliefs Within 10 PTS OF TRUTH } \\
\hline Treat & $\begin{array}{l}-0.52 \\
{[0.91]}\end{array}$ & $\begin{array}{l}-10.3 \\
{[4.05]}\end{array}$ & $\begin{array}{c}1.59 \\
{[3.67]}\end{array}$ & $\begin{array}{c}0.067 \\
{[0.072]}\end{array}$ & $\begin{array}{l}-0.47 \\
{[0.89]}\end{array}$ & $\begin{array}{c}0.070 \\
{[0.086]}\end{array}$ & $\begin{array}{c}0.84 \\
{[1.32]}\end{array}$ \\
\hline Observations & 1,571 & 1,299 & 1,657 & 1,589 & 579 & 550 & 541 \\
\hline
\end{tabular}

Notes: Data sources are baseline survey, baseline test score data, both endline surveys, and endline administrative data. Each observation is a child. Standard errors are clustered at the household level. Regressions control for school FE, average parental years of education, parent gender, the betweenchild score gap, child baseline performance, child gender, grade FE, and the baseline value of the dependent variable (baseline value not available for enrollment or experimental outcomes). The dependent variable in Column (1) corresponds to the parent's endline beliefs about the child's overall score on a hypothetical test taken the same day as the endline survey. Workbook difficulty choices are coded as 0 for beginner, 100 for average, 200 for advanced. Enrollment defined as being enrolled in school 1 year after the intervention; enrollment and attendance scaled to be out of 100 (so, for example, enrollment is equal to 100 if the child is still enrolled and 0 otherwise). Panel B uses the relevant measure of beliefs (e.g., overall for beliefs, math - English for textbooks; see Table 3 for details.) 
Appendix Table A.3: Asymmetric responses to positive vs. negative information shocks

\begin{tabular}{lcccc}
\hline \hline Dependent variable: & $\begin{array}{c}\text { Endline } \\
\text { beliefs }\end{array}$ & $\begin{array}{c}\text { Math } \\
\text { workbook } \\
\text { difficulty } \\
\text { level } \\
(2)\end{array}$ & $\begin{array}{c}\text { English } \\
\text { workbook } \\
\text { difficulty } \\
\text { level } \\
(3)\end{array}$ & Enrollment \\
\hline Treat $\times$ Score $\times$ Pos. Shock & 0.420 & 1.221 & 1.613 & 0.082 \\
& {$[0.041]$} & {$[0.179]$} & {$[0.149]$} & {$[0.121]$} \\
Treat $\times$ Score & 0.209 & 0.639 & 0.251 & 0.125 \\
& {$[0.030]$} & {$[0.107]$} & {$[0.111]$} & {$[0.044]$} \\
Score Used & & & & \\
Observations & Overall & Math & English & Overall \\
R-squared & 5,244 & 5,239 & 5,239 & 1,786 \\
\hline \hline
\end{tabular}

Notes: Data sources are baseline survey, baseline test score data, and the endline surveys. The table shows the results of estimating equation 1 (i.e., the equation estimated in Table 2, which shows how information affected the slope of the investment function), fully interacted with an indicator for whether a household was a "positive shock" household, where "positive shock" means that the child's true performance was higher than the parent's baseline beliefs. In the interest of brevity, not all coefficients are shown. The dependent variable in Column (1) corresponds to the parent's endline beliefs about the child's overall score on a hypothetical test taken the same day as the endline survey. Regressions control for school FE, grade FE, average parental years of education, parent gender, the between-child score gap, child baseline performance, child gender, and all of the main effects and interaction terms (i.e., Treat, Score, Pos. Shock, and all of their double interactions). Each observation is a child. Standard errors are clustered at the household level. 
Appendix Table A.4: Uncertainty tests: Effect of information on the slope of the preferred investment function

\begin{tabular}{|c|c|c|c|c|c|c|c|}
\hline & \multicolumn{4}{|c|}{ Experimental outcomes } & \multicolumn{3}{|c|}{ Non-experimental outcomes } \\
\hline & $\begin{array}{c}\text { Math } \\
\text { workbook } \\
\text { difficulty } \\
\text { level } \\
\text { (1) }\end{array}$ & $\begin{array}{c}\text { English } \\
\text { workbook } \\
\text { difficulty } \\
\text { level } \\
(2)\end{array}$ & $\begin{array}{c}\ln (\text { English } \\
\text { textbook } \\
\text { WTP) - } \\
\ln (\text { math } \\
\text { textbook } \\
\text { WTP }) \\
(3)\end{array}$ & $\begin{array}{c}\text { Lottery } \\
\text { tickets } \\
\\
(4)\end{array}$ & $\begin{array}{l}\text { Enrollment } \\
\qquad(5)\end{array}$ & $\begin{array}{l}\ln (\text { Total } \\
\text { educ. } \\
\text { expendi- } \\
\text { tures) } \\
(6)\end{array}$ & $\begin{array}{l}\text { Attendance } \\
\text { rate } \\
\text { (7) }\end{array}$ \\
\hline Treat $\times$ Score & $\begin{array}{c}0.36 \\
{[0.22]}\end{array}$ & $\begin{array}{c}0.39 \\
{[0.16]}\end{array}$ & $\begin{array}{l}0.00067 \\
{[0.0049]}\end{array}$ & $\begin{array}{c}0.018 \\
{[0.010]}\end{array}$ & $\begin{array}{c}0.15 \\
{[0.069]}\end{array}$ & $\begin{array}{c}-0.00049 \\
{[0.0050]}\end{array}$ & $\begin{array}{c}-0.11 \\
{[0.097]}\end{array}$ \\
\hline Score Measure & Math & English & $\begin{array}{l}\text { Math - } \\
\text { English }\end{array}$ & Score & Score & Score & Score \\
\hline $\begin{array}{l}\text { Treat } \times \text { Score }(\text { full sample }) \\
\text { p-val: Treat } \times \text { Score equal in full sample } \\
\text { Observations }\end{array}$ & $\begin{array}{l}1.336 \\
0.000 \\
1,106\end{array}$ & $\begin{array}{l}1.251 \\
0.000 \\
1,450 \\
\end{array}$ & $\begin{array}{l}0.014 \\
0.002 \\
1,416 \\
\end{array}$ & $\begin{array}{l}0.036 \\
0.051 \\
1,786 \\
\end{array}$ & $\begin{array}{c}0.105 \\
0.991 \\
534 \\
\end{array}$ & $\begin{array}{c}-0.002 \\
0.798 \\
508 \\
\end{array}$ & $\begin{array}{c}0.021 \\
0.401 \\
489 \\
\end{array}$ \\
\hline Treat $\times$ Score & $\begin{array}{c}1.64 \\
{[0.090]}\end{array}$ & $\begin{array}{c}1.67 \\
{[0.088]}\end{array}$ & $\begin{array}{c}0.015 \\
{[0.0021]}\end{array}$ & $\begin{array}{c}0.049 \\
{[0.0056]}\end{array}$ & $\begin{array}{c}0.100 \\
{[0.046]}\end{array}$ & $\begin{array}{c}-0.00050 \\
{[0.0025]}\end{array}$ & $\begin{array}{c}0.088 \\
{[0.053]}\end{array}$ \\
\hline Treat $\times$ Beliefs & $\begin{array}{l}-1.52 \\
{[0.10]}\end{array}$ & $\begin{array}{l}-1.55 \\
{[0.086]}\end{array}$ & $\begin{array}{c}-0.011 \\
{[0.0021]}\end{array}$ & $\begin{array}{c}-0.035 \\
{[0.0063]}\end{array}$ & $\begin{array}{c}0.017 \\
{[0.061]}\end{array}$ & $\begin{array}{l}-0.0036 \\
{[0.0028]}\end{array}$ & $\begin{array}{c}-0.18 \\
{[0.058]}\end{array}$ \\
\hline $\begin{array}{l}\text { p-val: }(\text { Treat } \times \text { Score }) \\
+(\text { Treat } \times \text { Beliefs })=0 \\
\text { p-val: Treat } \times \text { Score }=0 \\
\text { Observations }\end{array}$ & $\begin{array}{l}0.256 \\
0.000 \\
5,233\end{array}$ & $\begin{array}{l}0.216 \\
0.000 \\
5,233\end{array}$ & $\begin{array}{l}0.148 \\
0.000 \\
5,213\end{array}$ & $\begin{array}{l}0.028 \\
0.000 \\
5,250\end{array}$ & $\begin{array}{l}0.019 \\
0.032 \\
1,780\end{array}$ & $\begin{array}{l}0.123 \\
0.843 \\
1,703\end{array}$ & $\begin{array}{l}0.130 \\
0.093 \\
1,822\end{array}$ \\
\hline
\end{tabular}

Notes: Data sources are baseline survey, baseline test score data, the endline surveys, and endline administrative data. Panel A takes parents whose baseline beliefs were within 10 points of their children's true academic performance as the sample, and examines the treatment effect on the slope of investments on children's true score. Panel B uses the entire experimental sample and looks at the heterogeneity in the treatment effect on the gradients of investments on both the true score and parents' beliefs, where the prediction for no change in the slope of the preferred function (i.e., for no uncertainty effects) is that the coefficients are equal and opposite. Regressions control for school FE, parents' education, the between-child score gap, child baseline performance, grade fixed effects, the baseline value of the dependent variable (baseline value not available for enrollment or experimental outcomes), treatment, and the main effects of any variable interacted with treatment. Thus, both panels control for the main effect of true score, and panel B also controls for the main effect of beliefs. Standard errors clustered at the household level. Workbook difficulty choices are coded as 0 for beginner, 100 for average, and 200 for advanced. Enrollment defined as being enrolled in school 1 year after the intervention; enrollment and attendance scaled to be out of 100 (so, for example, enrollment is equal to 100 if the child is still enrolled and 0 otherwise). 


\section{B Sample information intervention report card}

\begin{tabular}{|c|c|c|c|}
\hline \multicolumn{4}{|c|}{ Report Card } \\
\hline \multirow[t]{2}{*}{ Name: NDI } & \multicolumn{2}{|c|}{ Standard: 2} & \multirow[b]{2}{*}{ Position } \\
\hline & $\underline{\text { Score }}$ & Grade & \\
\hline Maths: & $75 / 100$ & 3 & $10 / 100$ \\
\hline English: & $33 / 100$ & 1 & $71 / 100$ \\
\hline Chichewa: & $67 / 100$ & 3 & $38 / 100$ \\
\hline Overall: & $58 / 100$ & 2 & $52 / 100$ \\
\hline \multicolumn{4}{|c|}{ Number of Exams Administered in Class: 3} \\
\hline \multicolumn{4}{|c|}{$\begin{array}{c}\text { Grades } \\
1=\text { Needs support } \\
2=\text { Average } \\
3=\text { Good } \\
4=\text { Excellent }\end{array}$} \\
\hline
\end{tabular}

Note: "Positions" are a measure of children's relative performance within their classes, equal to 100 minus the percentile. For ease of interpretation, the measure is converted to percentiles for the analysis. See Online Appendix Section J.3 for details. 


\section{Appendix to Section 2 (Empirical approach)}

\section{C.1 Discussion of Predictions 1 and 2}

\section{C.1.1 Prediction 1: Attenuation in the slope of the actual investment function}

We want to show that if (i) beliefs are an "attenuated" function of true performance (i.e., have a slope less than 1 if regressed on true performance), and (ii) the preferred investment function $s^{*}(\cdot)$ is either linear or monotonic, then the slope of the actual investment function $\tilde{s}(\cdot)$ will be lower in magnitude than the slope of the preferred function. For expositional simplicity, I focus on the linear case. ${ }^{33}$

Write the preferred investment function as: $s^{*}(\alpha)=\beta_{0}+\beta_{1} \alpha$, with $s$ being the investment and $\alpha$ representing the parent's beliefs about the child's performance. The slope of the preferred investment function (i.e., the slope of investments on beliefs) is thus $\beta_{1}$, and, using the standard OLS formula, the slope of the actual investment function (i.e., the slope of investments on true performance) is $\frac{\operatorname{cov}\left(\beta_{0}+\beta_{1} \alpha, a\right)}{\operatorname{var}(a)}=\beta_{1} \frac{\operatorname{cov}(\alpha, a)}{\operatorname{var}(a)}$. Thus, whenever $\frac{\operatorname{cov}(\alpha, a)}{\operatorname{var}(a)} \neq 1$, inaccurate beliefs will cause the actual slope to differ from the preferred slope, and whenever $\frac{\operatorname{cov}(\alpha, a)}{\operatorname{var}(a)}<1$, there is attenuation. Since $\frac{\operatorname{cov}(\alpha, a)}{\operatorname{var}(a)}$ is the slope from regressing believed performance on true performance, this means that the condition for attenuation in the slope of $\tilde{s}(\cdot)$ is that beliefs are an attenuated function of true performance, i.e., have a slope less than 1.

\section{C.1.2 Prediction 2: If there is baseline attenuation, information increases the slope of investments}

Denote the preferred investment function as $s^{*}(\alpha)=\beta_{0}+\beta_{1} \alpha$. Chosen investments thus equal $s^{*}(\alpha)+\varepsilon=\beta_{0}+\beta_{1} \alpha+\varepsilon{ }^{34}$ I first outline the bias in an observational data approach, and then outline how an experiment addresses this bias. The observational approach would be to compare the slopes estimated from regressing baseline (or control group) $s$ on $\alpha$ with the slope from regressing baseline $s$ on $a$. The slope from regressing on $\alpha$ will be the true causal slope, $\beta_{1}$, plus an omitted variable bias (OVB) term, $\frac{\operatorname{cov}(\alpha, \varepsilon)}{\operatorname{var}(\alpha)}$. The slope from regressing on $a$ will be the true causal slope derived above in Appendix Section C.1.1, $\beta_{1} \frac{\operatorname{cov}(\alpha, a)}{\operatorname{var}(a)}$, plus an OVB term: $\frac{\operatorname{cov}(a, \varepsilon)}{\operatorname{var}(a)}$. Thus, the difference in slopes will be $\left(\beta_{1}-\beta_{1} \frac{\operatorname{cov}(\alpha, a)}{\operatorname{var}(a)}\right)+\left(\frac{\operatorname{cov}(\alpha, \varepsilon)}{\operatorname{var}(\alpha)}-\frac{\operatorname{cov}(a, \varepsilon)}{\operatorname{var}(a)}\right)$ and so will only give us an unbiased estimate of the true difference in slopes, $\beta_{1}-\beta_{1} \frac{\operatorname{cov}(\alpha, a)}{\operatorname{var}(a)}$, if the second term (i.e., the difference between the OVB terms $\left.\left(\frac{\operatorname{cov}(\alpha, \varepsilon)}{\operatorname{var}(\alpha)}-\frac{\operatorname{cov}(a, \varepsilon)}{\operatorname{var}(a)}\right)\right)$ is equal to 0 .

\footnotetext{
${ }^{33}$ In the nonlinear case, for some $s^{*}(\cdot)$, certain additional restrictions on the joint distribution of $a$ and $\alpha$ are needed, for example that $a$ and $\alpha$ have the same variance.

${ }^{34}$ Note that, for expositional simplicity, I focus on the linear case, but one can interpret this as the best linear predictor function in the case where investments are non-linear in $\tilde{A}$.
} 
An experiment can solve this problem. Consider comparing the slopes of the actual investment functions ( $s$ regressed on $a$ ) for parents who have received information about $a$, (treatment group) vs. those who have not (control group). Parents in the treatment group will now base investments on true performance $a$, so their investments will be $s^{*}(a)+\varepsilon=$ $\beta_{0}+\beta_{1} a+\varepsilon{ }^{35}$ The slope in the treatment group will thus be $\beta_{1}+\frac{\operatorname{cov}(a, \varepsilon)}{\operatorname{var}(a)}$, whereas in the control group it will be the same as above: $\beta_{1} \frac{\operatorname{cov}(\alpha, a)}{\operatorname{var}(a)}+\frac{\operatorname{cov}(a, \varepsilon)}{\operatorname{var}(a)}$. Since, unlike for the observational approach, the omitted variable terms are now identical, comparing the slope between treatment and control groups will allow us to estimate the true difference in slopes $\left|\beta_{1}-\beta_{1} \frac{\operatorname{cov}(\alpha, a)}{\operatorname{var}(a)}\right|$. If investments were attenuated at baseline, that difference will be positive, meaning that information will increase the magnitude of the slope.

\section{C.2 Uncertainty predictions}

There are many ways to model uncertainty in beliefs. Here, I show one potential framework which yields the prediction that uncertainty in parents' beliefs about academic performance leads to attenuation in the slope of investments on mean beliefs $\alpha$. The framework captures the intuition described in the main text: that uncertainty in parents' beliefs may make them hesitate to make their investments depend as strongly on their mean beliefs. This is a richer model than the one used in Section 2.

Assume there is some true unobserved underlying academic skill. Call this a and call parents' beliefs about it $\boldsymbol{\alpha}$. Assume this underlying academic skill is what determines returns and is thus what parents truly want to base decisions on. Assume further that academic skill is distinct from academic performance, $a$, where $a$ is what we measured baseline beliefs on, and what we delivered information about in the intervention; instead, academic performance $a$ is taken by parents as a signal of $\mathbf{a}$.

In this context, we can model beliefs about academic skill $\boldsymbol{\alpha}$ as being a convex combination of beliefs about school performance, $\alpha$, and beliefs about all other aspects or signals of academic skills, $\boldsymbol{\alpha}_{-\alpha}$, given by:

$$
\boldsymbol{\alpha}=\lambda \alpha+(1-\lambda) \boldsymbol{\alpha}_{-\alpha}
$$

where $\lambda$ is the weight on the academic performance.

Since preferred investments would be a function of $\boldsymbol{\alpha}$, not $\alpha$, we could write the preferred investment function as $\tilde{s}^{*}(\boldsymbol{\alpha})$. For expositional simplicity, let's look at the linear case where $\tilde{s}^{*}(\boldsymbol{\alpha})=\tilde{\beta}_{0}+\tilde{\beta}_{1} \boldsymbol{\alpha}$ (where the $\tilde{\beta}_{1}$ notation distinguishes this from the preferred invest-

\footnotetext{
${ }^{35}$ Note that this assumes that parents fully update their beliefs in response to the intervention. If they only partially update their beliefs, then the difference in slope between treatment and control groups would be weighted downwards by the updating parameter (i.e., if updated beliefs were a weighted combination of $a$ and $\alpha$ with $\gamma$ the weight on $a$, then the difference in slopes would uncover $\left.\gamma\left(\beta_{1}-\beta_{1} \frac{\operatorname{cov}(\alpha, a)}{\operatorname{var}(a)}\right)\right)$.
} 
ment function in the simpler model from Section 2 and Appendix Section C.1.) Preferred investments could then be written as:

$$
\begin{aligned}
s^{*}(\boldsymbol{\alpha}) & =\tilde{\beta}_{0}+\tilde{\beta}_{1} \boldsymbol{\alpha} \\
& =\tilde{\beta}_{0}+\tilde{\beta}_{1} \lambda \alpha+\tilde{\beta}_{1}(1-\lambda) \boldsymbol{\alpha}_{-\alpha}
\end{aligned}
$$

In this context, providing information about academic performance, $a$, should increase the certainty of parents' beliefs distributions (i.e., decrease $\sigma^{2}$ ). This could increase the weight that parents place on beliefs about academic performance $\alpha$ when forming their beliefs about underlying academic skill $\boldsymbol{\alpha}$, that is, increase $\lambda$. Since $\lambda$ increases, under most assumptions for the form that $\boldsymbol{\alpha}_{-\alpha}$ would take, ${ }^{36}$ the slope of investments on beliefs about school performance $\alpha$ should also increase.

Note that this is a channel for uncertainty to change the slope of investments on beliefs about academic performance, $\alpha$, even if the underlying slope of the true preferred investment function on beliefs about academic skill, ã, does not change. ${ }^{37}$

\section{Results for secondary outcomes}

In the endline survey, I also collected data on two outcomes which I considered secondary because I did not have ex ante hypotheses that there would be effects or because expected power was low: transfers across schools, and non-monetary investments such as giving the child fewer chores or homework assistance. For completeness, these results are presented in Online Appendix Table G.14. Parents indicated ex ante that non-monetary investments would respond to their children's performance, but expected power was low since it is difficult to measure these investments cleanly. I find positive average treatment effects, but no significant impact on the slope. For transfers across schools, parents did not indicate ex ante that it was a margin which would respond. However, information increases transfers (defined as an indicator that the child transferred schools, not conditional on enrollment) by $50 \%$, from $6 \%$ to $9 \%$. Although there is no change in the slope on performance, heterogeneity in the preferred slope by school type could explain this. At low-quality schools, finding out a child is doing well might make it worth the effort costs of changing him to a better school, so

\footnotetext{
${ }^{36}$ Specifically, the regression of investments on $\alpha$ would have slope $\lambda \beta_{1}+(1-\lambda) \beta_{1} \frac{\operatorname{cov}\left(\alpha, \boldsymbol{\alpha}_{-\alpha}\right)}{\operatorname{Var}(\alpha)}=\lambda \beta_{1}+(1-$ $\lambda) \beta_{1} \operatorname{corr}\left(\alpha, \boldsymbol{\alpha}_{-\alpha}\right) \frac{s d\left(\boldsymbol{\alpha}_{-\alpha}\right)}{s d(\alpha)}$. Thus, since $\operatorname{corr}\left(\alpha, \boldsymbol{\alpha}_{-\alpha}\right) \leq 1$, increasing $\lambda$ should increase the slope as long as the variance of $\boldsymbol{\alpha}_{-\alpha}$ is not too much larger than the variance of $\alpha$.

${ }^{37}$ For example, with a linear preferred investment function and a quadratic loss function, the slope of the true preferred investment function should not change. It is useful to note that in this richer model, although providing information about $a$ should unambiguously increase the certainty of $\alpha$, it is ambiguous whether it will decrease or increase the uncertainty of beliefs about a. For example, if the information were very different from parents' prior beliefs, it could increase the uncertainty of beliefs about a.
} 
transfers would be positively sloped with performance. In contrast, at high-quality schools, finding out a child is doing poorly could indicate a poor match, and so transfers would have the opposite slope. Indeed, if we look at the results separately by school quality (proxied by school-average achievement), there are slope effects, with the slope becoming more positive at low-quality schools and more negative at high-quality schools (Online Appendix Table G.15). Of course, this is just one of many potential explanations - and it implicitly assumes that parents know school quality, which may not be the case - but the results are suggestive.

\section{E Discussion of the absence of an ATE for enrollment}

Parents on average overestimate their children's performance at baseline, and, for enrollment, invest more in their higher performers. This suggests that providing information might decrease enrollment. However, we do not find a significant effect. There are several potential (non-mutually-exclusive) explanations. First, uncertainty in the control group may decrease investment, akin to uncertainty dampening investment in risky assets. However, I do not observe a positive average level effect for the parents who had more accurate beliefs at baseline, though the power of the test is low (see Panel B of Appendix Table A.2). Second, parents may already be spending as much as they can on education, and so the effect of information is primarily on the allocation of spending, not the level. Unfortunately this channel is difficult to test. Third, parents' reported beliefs may be biased upwards somewhat relative to true beliefs. This channel is also unfortunately difficult to test. Fourth, parents could respond more to positive than to negative information; I explore this channel in detail below. Finally, we may lack statistical precision.

\section{Result: Investments respond more to positive than negative shocks.}

Appendix Table A.3 shows the results from estimating equation 1, fully interacted with a dummy for receiving a positive information shock $\left(A_{i j}>\tilde{A_{i j}}\right)$. The model is estimated for all outcomes for which (a) one direction of shock is unambiguously positive (e.g., the secondary school lottery depends on between-child performance and so neither direction is "positive"; thus, that outcome is not included); and (b) there is a treatment effect on the slope in the full sample. The change in slope (coefficient on Treat $\times$ Score) is larger for parents who receive positive information shocks. ${ }^{38}$ For enrollment, precision is lacking, but the magnitude of the coefficient is large, suggesting that this channel could help explain why there is no negative ATE for enrollment.

\footnotetext{
${ }^{38}$ It would potentially be concerning if the positive information shocks were larger, but that is not the case: The absolute gap between believed and true performance is roughly $40 \%$ smaller for the positive information shock sample. Another potential concern is that some actions are bounded (e.g., one cannot choose a less difficult workbook than beginner), but restricting the sample to parents whose predicted behavior (based on baseline beliefs) is in the middle of the range of potential outcomes yields similar results.
} 


\section{F Mechanisms: The role of uncertainty in beliefs}

My primary analyses show that information increases the slope of investments on true performance, thus suggesting that the slope was attenuated at baseline. As discussed in Section 2, both inaccuracies in the mean of baseline beliefs and uncertainty of baseline beliefs could cause that baseline attenuation. A reasonable question is thus whether the channel for the treatment effects is an effect on the mean or on the uncertainty of beliefs. The analysis of the channels is suggestive in nature, since I did not experimentally vary uncertainty separately from the mean, nor (for budget reasons) did I measure uncertainty at endline. Under an uncertainty channel, uncertainty could decrease the preferred slope of investments as a function of mean beliefs, since parents may not want to invest as steeply based on their mean beliefs if their beliefs are uncertain. ${ }^{39}$ The attenuation of preferred investments on beliefs would then cause attenuation of actual investments on true performance - which is the attenuation that has been the focus of the analysis so far. In contrast, under the channel of inaccurate means, the slope of investments as a function of mean beliefs is not attenuated; rather, the attenuation of investments on true performance stems from the fact that, because beliefs are inaccurate, they themselves are attenuated functions of true performance. As a result, one empirical signature of the uncertainty channel is attenuation of investments on beliefs themselves; to assess uncertainty's role, I test whether information increases the slope of investments on beliefs. I use two approaches; both suggest that the primary mechanism for reallocations across types of investments (e.g., difficulty levels of workbooks) is changes to the mean/accuracy of beliefs, but that changes to the uncertainty of beliefs matter more for the larger investments that proxy more for the level of investment.

The first approach looks at the treatment effect on the slope for those who have relatively accurate beliefs at baseline. For this group, there is no belief accuracy effect of information (since beliefs were accurate to begin with). Any slope change therefore will likely represent an uncertainty effect. Panel A of Appendix Table A.4 shows the results of estimating equation 1 for parents whose beliefs regarding their children's performance were within 10 points of the true score. For the smaller investments, such as workbooks, the slope for these parents changes a little (i.e., there is a small uncertainty effect), but the effect is only $30 \%$ of the magnitude - and significantly different from - the change in slope in the full sample. This suggests that the effect presented earlier for the full sample is driven primarily by changes to belief accuracy. This is not surprising, since the preferred investment function was already steeply sloped in the control group. For the larger investments, on the other hand, the uncertainty effects are larger, with effects in the accurate beliefs sample representing $50 \%$ of the coefficient estimated in the full sample for the lottery, and $100 \%$ for enrollment. Of

\footnotetext{
${ }^{39}$ See Appendix C.2 for a framework yielding this prediction.
} 
course, a key caveat to interpretation is that parents with accurate beliefs could be different from other parents; for example, they could have more certain beliefs.

A second approach is to test whether the heterogeneity in the treatment effect by performance is equal and opposite to the heterogeneity by baseline beliefs. Suppose preferred investments as a function of baseline beliefs take the form $\beta_{0}+\beta_{1} \alpha$. If information does not change the preferred slope, this means that information simply moves parents along the preferred function by the amount of the information shock $(a-\alpha)$. In that case, the treatment effect would be $\beta_{1}(a-\alpha)$, and the coefficients on Treat $\times a$ and Treat $\times \alpha$ would be equal and opposite: $\beta_{1}$ and $-\beta_{1}$, respectively. If, instead, the magnitude of the coefficient on Treat $\times a$ is larger than that of Treat $\times \alpha$, it suggests that beliefs about academic performance are more important to treatment parents' investments than to control parents', i.e., the slope of investments on beliefs has increased. To see this, denote the slope of the investment function in the control (treatment) group $\beta_{1}^{C}\left(\beta_{1}\right)$. Parent $i$ with baseline beliefs $\alpha_{i}$ and true performance $a_{i}$ would have investment of $s^{C}\left(\alpha_{i}\right)=\beta_{0}^{C}+\beta_{1}^{C} \alpha_{i}$ in the control group, and $s\left(a_{i}\right)=\beta_{0}+\beta_{1} a_{i}$ in the treatment group. Thus, the treatment effect as a function of $a$ and $\alpha$ is $\tau\left(a_{i}, \alpha_{i}\right)=s\left(a_{i}\right)-s^{C}\left(\alpha_{i}\right)=\left(\beta_{0}-\beta_{0}^{C}\right)+\beta_{1} a_{i}-\beta_{1}^{C} \alpha_{i}$, and so heterogeneity in the treatment effect by $a$ identifies $\beta_{1}$ and heterogeneity by $\alpha$ identifies $-\beta_{1}^{C}$.

Panel B of Appendix Table A.4 shows that the results are consistent with the previous test, since the lottery and enrollment are the only investments where we can reject that the coefficients are equal and opposite. ${ }^{40}$

To assess whether these slope changes do in fact reflect uncertainty, I can look at heterogeneity in both of the above tests by a baseline measure of the uncertainty of beliefs. Power is low and so the results are somewhat inconclusive; reassuringly, however, the only coefficient significant at the 10\% level (English workbooks) does suggest that the slope increases more for parents with more uncertain beliefs. See Online Appendix Table G.16.

This section focused on a specific effect of uncertainty on investments, namely, whether changes to uncertainty contributed to the core treatment effects analyzed in this paper: the treatment effects of information on the alignment of investments with performance. Uncertainty can also affect investments in other ways that are not the focus of this paper (see, for example, Bobba and Frisancho (2016)).

\footnotetext{
${ }^{40}$ Note that this test can also be seen as a test for whether it would be appropriate to use a "beliefs shock" specification for analyzing the treatment effects of information (i.e., a specification that looks at treatment effect heterogeneity by $a-\alpha$ ), since that specification assumes that the coefficients on Treat $\times a$ and Treat $\times \alpha$ are equal and opposite. Since that assumption is rejected for the lottery and primary school enrollment, the "beliefs shock" specification is not appropriate for examining those outcomes, but it would be for the other outcomes. For completeness, results on heterogeneity by "beliefs shock" are shown in Online Appendix Table G.17. For the investments where the assumption was not rejected, the results are consistent.
} 